Chapman University

Chapman University Digital Commons

Pharmacy Faculty Articles and Research

School of Pharmacy

8-4-2017

\title{
Traceable PEO-poly(ester) Micelles for Breast Cancer Targeting: The Effect of Core Structure and Targeting Peptide on Micellar Tumor Accumulation
}

\author{
Shyam M. Garg \\ University of Alberta \\ Igor M. Paiva \\ University of Alberta \\ Mohammad R. Vakili \\ University of Alberta \\ Rania Soudy \\ University of Alberta \\ Kate Agopsowicz \\ University of Alberta \\ Follow this and additional works at: http://digitalcommons.chapman.edu/pharmacy_articles \\ 'patt page for thditional authors \\ Pharmaceutical Chemistry Commons, Medicinal-Pharmaceutical Chemistry Commons, and the \\ Other Medicine and Health Sciences Commons
}

\section{Recommended Citation}

Garg SM, Paiva IM, Vakili MR, et al. Traceable PEO-poly(ester) micelles for breast cancer targeting: The effect of core structure and targeting peptide on micellar tumor accumulation. Biomaterials. 2017;144:17-29. doi: 10.1016/j.biomaterials.2017.08.001.

This Article is brought to you for free and open access by the School of Pharmacy at Chapman University Digital Commons. It has been accepted for inclusion in Pharmacy Faculty Articles and Research by an authorized administrator of Chapman University Digital Commons. For more information,

please contact laughtin@chapman.edu. 


\section{Traceable PEO-poly(ester) Micelles for Breast Cancer Targeting: The Effect of Core Structure and Targeting Peptide on Micellar Tumor Accumulation}

Comments

NOTICE: this is the author's version of a work that was accepted for publication in Biomaterials. Changes resulting from the publishing process, such as peer review, editing, corrections, structural formatting, and other quality control mechanisms may not be reflected in this document. Changes may have been made to this work since it was submitted for publication. A definitive version was subsequently published in Biomaterials, volume 144, in 2017. DOI: 10.1016/j.biomaterials.2017.08.001

The Creative Commons license below applies only to this version of the article.

\section{Creative Commons License}

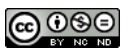

This work is licensed under a Creative Commons Attribution-Noncommercial-No Derivative Works 4.0 License.

\section{Copyright}

Elsevier

\section{Authors}

Shyam M. Garg, Igor M. Paiva, Mohammad R. Vakili, Rania Soudy, Kate Agopsowicz, Amir H. Soleimani, Mary Hitt, Kamaljit Kaur, and Afsaneh Lavasanifar 


\section{Accepted Manuscript}

Traceable PEO-poly(ester) micelles for breast cancer targeting: The effect of core structure and targeting peptide on micellar tumor accumulation

Shyam M. Garg, Igor M. Paiva, Mohammad R. Vakili, Rania Soudy, Kate Agopsowicz, Amir Soleimani, Mary Hitt, Kamaljit Kaur, Afsaneh Lavasanifar

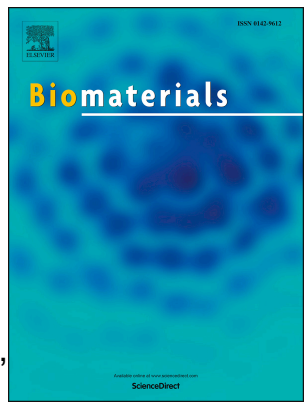

PII:

S0142-9612(17)30504-5

DOI:

10.1016/j.biomaterials.2017.08.001

Reference: JBMT 18202

To appear in: Biomaterials

Received Date: 10 June 2017

Revised Date: 14 July 2017

Accepted Date: 1 August 2017

Please cite this article as: Garg SM, Paiva IM, Vakili MR, Soudy R, Agopsowicz K, Soleimani A, Hitt M, Kaur K, Lavasanifar A, Traceable PEO-poly(ester) micelles for breast cancer targeting: The effect of core structure and targeting peptide on micellar tumor accumulation, Biomaterials (2017), doi: 10.1016/ j.biomaterials.2017.08.001.

This is a PDF file of an unedited manuscript that has been accepted for publication. As a service to our customers we are providing this early version of the manuscript. The manuscript will undergo copyediting, typesetting, and review of the resulting proof before it is published in its final form. Please note that during the production process errors may be discovered which could affect the content, and all legal disclaimers that apply to the journal pertain. 


\section{Traceable PEO-poly(ester) Micelles for Breast}

\section{Cancer Targeting: The Effect of Core Structure and}

\section{Targeting Peptide on Micellar Tumor Accumulation}

Shyam M. Garg ${ }^{1}$, Igor M. Paiva ${ }^{1}$, Mohammad R. Vakili ${ }^{1}$, Rania Soudy ${ }^{1}$, Kate Agopsowicz ${ }^{3}$, Amir Soleimani ${ }^{1}$, Mary Hitt ${ }^{3}$, Kamaljit Kaur ${ }^{1,4}$, Afsaneh Lavasanifar ${ }^{1,2} *$

${ }^{1}$ Faculty of Pharmacy and Pharmaceutical Sciences, University of Alberta, Edmonton, Alberta, Canada, T6G 2E1

${ }^{2}$ Department of Chemical and Materials Engineering, Faculty of Engineering, University of Alberta, Edmonton, AB

${ }^{3}$ Department of Oncology, Faculty of Medicine and Dentistry, University of Alberta, Edmonton, Alberta, Canada, T6E 2E1

${ }^{4}$ Chapman University School of Pharmacy (CUSP), Harry and Diane Rinker Health Science Campus, Chapman University, Irvine, CA, 92618-1908, USA

*Corresponding author: afsaneh@ualberta.ca 
Abstract

Traceable poly(ethylene oxide)-poly(ester) micelles were developed through chemical conjugation of a near-infrared (NIR) dye to the poly(ester) end by click chemistry. This strategy was tried for micelles with poly( $\varepsilon$-caprolactone) (PCL) or poly $(\alpha$-benzyl carboxylate- $\varepsilon$ caprolactone) (PBCL) cores. The surface of both micelles was also modified with the breast cancer targeting peptide, P18-4. The results showed the positive contribution of PBCL over PCL core on micellar thermodynamic and kinetic stability as well as accumulation in primary orthotopic MDA-MB-231 tumors within 4-96 h following intravenous administration in mice. This was in contrast to in vitro studies where better uptake of PEO-PCL versus PEO-PBCL micelles by MDA-MB-231 cells was observed. The presence of P18-4 enhanced the in vitro cell uptake and homing of both polymeric micelles in breast tumors, but only at early time points. In conclusion, the use of developed NIR labeling technique provided means for following the fate of PEO-poly(ester) based nano-carriers in live animals. Our results showed micellar stabilization through the use of PBCL over PCL cores, to have a more significant effect in enhancing the level and duration of nano-carrier accumulation in primary breast tumors than the modification of polymeric micellar surface with breast tumor targeting peptide, $\mathrm{P} 18-4$ peptide.

Keywords: Breast cancer, nanocarriers, living imaging, polymeric micelles, biodistribution. 


\section{Introduction}

Proper design and development of nanocarriers capable of tumor accumulation and targeted drug delivery has been the focus of several studies in recent years. The common practice is to modify the chemical structure of biomaterial building blocks, in order to optimize the size, morphology and stability of self-assembled nanostructures for passive accumulation into solid tumors through enhanced permeation and retention (EPR) effect [1-3]. Surface modification with targeting ligands can also be pursued to enhance the homing and interaction of nanoparticles with tumor cells. Success of the latter approach would depend on finding the appropriate ligand at the optimum ligand surface density [4,5]. Development of traceable nanocarriers, which can be visualized in live animals, can expedite their optimization process for enhanced drug delivery to tumor cells. Traceable nanocarriers can also be further developed for use in the personalization of cancer therapy, detection of cancer progress and/or monitoring of treatment outcome in patients $[6,7]$.

The objective of this study was to, first, develop traceable poly(ethylene oxide)-poly( $\varepsilon$ caprolactone) (PEO-PCL) based polymeric micelles; then use this technology to investigate the effect of adding a hydrophobic pendent group (i.e. aromatic, benzyl group) on the PCL block as well as a surface peptide ligand on the in vivo biodistribution of the corresponding nanocarriers in a breast tumor-bearing animal model.

Self-assembled nanostructures composed of poly(ethylene oxide)-poly(ester)s such as PEO-PCL [8-11], poly(ethylene oxide)-poly(lactide) (PEO-PLA) [12,13], and poly(ethylene oxide)-poly(lactide-co-glycolide) (PEO-PLGA) [14,15] have been the subject of tremendous research for drug solubilization and targeted delivery in cancer [16]. The increasing interest in the use of these structures is due to their biocompatibility, biodegradability and safe history of 
use in human $[17,18]$. However, despite a long history of use as drug delivery systems, limited information on the effect of structural features affecting core hydrophobicity and thus micellar stability among nanocarriers formed from poly(ethylene oxide)-poly(ester)s on their biodistribution and in vivo tumor targeting is available [5,19-21]. Previously, we have reported on the development of novel self-associating PEO-poly(ester) based block copolymers through introduction of pendant benzyl carboxylate groups to the PCL segment of PEO-PCL leading to the production of PEO-poly( $\alpha$-benzyl carboxylate- $\varepsilon$-caprolactone) (PEO-PBCL) [22]. This modification, according to our in vitro studies, increases the kinetic and thermodynamic stability, and also decreases the rate of degradation of polymeric micelles formed through self-association of these block copolymers [23]. In the current study, traceable nanocarriers based on PEO-PCL and PEO-PBCL were developed through chemical conjugation of a near infrared dye (NIR) to their core-forming block for live imaging of mice bearing tumors. The NIR labeling provided means to assess the effect of core structure on the extent and kinetics of primary tumor accumulation, for plain nanocarriers as well as those surface-modified with a novel breast tumor targeting peptide, P18-4, in an orthotopic breast cancer mouse model.

\section{Materials and methods}

\subsection{Materials}

Methoxy-polyethylene oxide (PEO) (average molecular weight of $5000 \mathrm{~g} / \mathrm{mol}$ ) and cholera toxin were purchased from Sigma (St. Louis, MO). $\varepsilon$-Caprolactone was purchased from Lancaster Synthesis (UK). $\alpha$-Benzyl carboxylate-e-caprolactone monomer was synthesized by Alberta Research Chemicals Inc (Edmonton, $\mathrm{AB}$ ) according to a previously published procedure 
[22]. $\alpha$-Propargyl carboxylate- $\varepsilon$-caprolactone (PCC) monomer was synthesized according to a previously published procedure [24]. Stannous octoate was purchased from MP Biomedicals Inc. (Germany). Cy5.5-azide was purchased from Lumiprobe (Hallandale Beach, FL). Cell culture media MEM, fetal bovine serum (FBS), sodium pyruvate, L-glutamine, non-essential amino acids, and penicillin-streptomycin-fungizone (Anti-Anti) were purchased from GIBCO, Life Technologies Inc. (Burlington, ON, Canada). MEGM medium kit was purchased from Lonza (Basel, Switzerland). Peptide P18-4 was synthesized according to a previously published procedure [25]. 2014S Teklad Global 14\% protein rodent maintenance diet was purchased from Harlan Labs (Indianapolis, IN). Spectra/por dialysis tubing (MWCO - $3.5 \mathrm{kDa}$ ) was purchased from Spectrum Laboratories (Rancho Dominguez, CA). Dry toluene was prepared by refluxing under $\mathrm{H}_{2} \mathrm{SO}_{4}$. All other chemicals were reagent grade.

\subsection{Cell lines}

The luciferase expressing human breast cancer cell line MDA-MB-231 (clone D3H2LN) was purchased from Caliper Life Sciences (Woodbridge, ON, Canada). The MDA-MB-231-lucD3H2LN cells were grown in MEM medium supplemented with $10 \%$ FBS, $1 \mathrm{mM}$ sodium pyruvate, $0.1 \mathrm{mM}$ non-essential amino acids (NEAA), $2 \mathrm{mM}$ L-glutamine, $100 \mathrm{IU} / \mathrm{mL}$ penicillin, $100 \mu \mathrm{g} / \mathrm{mL}$ streptomycin, and $0.25 \mu \mathrm{g} / \mathrm{mL}$ fungizone at $37{ }^{\circ} \mathrm{C}$ in $5 \% \mathrm{CO}_{2}$ atmosphere. The human mammary cell line MCF10A was purchased from ATCC (Manassas, VA). The MCF10A cells were grown in MEGM medium kit supplemented with $100 \mathrm{ng} / \mathrm{mL}$ cholera toxin at $37{ }^{\circ} \mathrm{C}$ in $5 \% \mathrm{CO}_{2}$ atmosphere.

\subsection{Synthesis of Cy5.5 conjugated block copolymers}


Block copolymers of PEO-PCL and PEO-PBCL were synthesized by ring-opening polymerization of $\varepsilon$-caprolactone $(0.1 \mathrm{~g})$ or $\alpha$-benzyl carboxylate- $\varepsilon$-caprolactone $(0.2 \mathrm{~g})$, respectively, using methoxy-PEO (MW: $5000 \mathrm{~g} / \mathrm{mol})(0.5 \mathrm{~g})$ as initiator and stannous octoate as catalyst according to a method described previously $[8,22,26]$.

Block copolymers of PEO-PCL or PEO-PBCL were end capped with $\alpha$-propargyl carboxylate- $\varepsilon$-caprolactone (PCC) using stannous octoate as catalyst. Briefly, PEO-PCL $(0.1 \mathrm{~g})$ and PCC $(0.014 \mathrm{~g})$ or, PEO-PBCL $(0.1 \mathrm{~g})$ and PCC $(0.012 \mathrm{~g})$ were added to a $25 \mathrm{~mL}$ roundbottom flask previously filled with $5 \mathrm{~mL}$ dry toluene under constant stirring. Stannous octoate (0.010 equiv of monomer) was added to the flask. The flask was then refluxed for $30 \mathrm{~h}$. The reaction was terminated by cooling the product to room temperature. The product was then precipitated in hexane and the supernatant was discarded. The final product was washed with ether and dried under vacuum for further use.

Near-infrared fluorophore (NIRF) Cy5.5-azide was conjugated to the terminal alkyne of PCC in PEO-PCL-PCC or PEO-PBCL-PCC using Huisgens 1,3-dipolar cycloaddition (azidealkyne click chemistry) reaction. The terminal alkyne group of PCC reacted with the terminal azide group of Cy5.5 azide to form a 1,3-triazole ring. $\mathrm{Cu}(\mathrm{I})$ acts as a catalyst for the reaction. $\mathrm{Cu}(\mathrm{I})$ is prepared in situ by the addition of $\mathrm{Cu}(\mathrm{II})$ TBTA Complex, and ascorbic acid, reducing $\mathrm{Cu}(\mathrm{II})$ to $\mathrm{Cu}(\mathrm{I})$. Briefly, $10 \mu \mathrm{mol}$ PEO-PCL-PCC (68 mg) or PEO-PBCL-PCC (75 mg) was dissolved under constant stirring in a $10 \mathrm{~mL}$ round-bottom flask containing $2 \mathrm{~mL}$ degassed DMSO. Cy5.5 azide ( $1 \mu \mathrm{mol} ; 0.7 \mathrm{mg})$ was dissolved in $400 \mu \mathrm{L}$ DMSO and added to the mixture under constant stirring followed by addition of ascorbic acid $(0.5 \mu \mathrm{mol} ; 0.1 \mathrm{mg})$ previously dissolved in $100 \mu \mathrm{L}$ water. The flask was then degassed with argon for about $30 \mathrm{~s} .10 \mathrm{mM} \mathrm{Cu}-$ TBTA Complex solution $(0.5 \mu \mathrm{mol} ; 60 \mu \mathrm{L})$ was finally added followed by degassing for $30 \mathrm{~s}$ 
using argon. The reaction mixture was sealed and incubated with stirring at room temperature in the dark for $16 \mathrm{~h}$. Argon was flushed through the sealed vial at 4 and $8 \mathrm{~h}$ time-points. After incubation, the mixture was separated from the non-reacted dye by dialysis against DMSO for 24 $\mathrm{h}$ followed by dialysis against water for $24 \mathrm{~h}$ to remove the DMSO, and then lyophilized.

\subsection{Synthesis of P18-4 modified block copolymers}

Acetal-PEO-PCL and acetal-PEO-PBCL were synthesized according to a previously published procedure [27]. P18-4-attached PEO-PCL or PEO-PBCL were synthesized from acetal-PEO-PCL or acetal-PEO-PBCL according to a previously published procedure $[5,28]$. Briefly, acetal-PEO-PCL and acetal-PEO-PBCL block copolymer micelles were prepared through formation of micelles $(6 \mathrm{mg} / \mathrm{mL})$ by a co-solvent evaporation method as described previously [8,22]. The micellar solution was then acidified to $\mathrm{pH} 2$ with $0.5 \mathrm{M} \mathrm{HCl}$ and stirred for $2 \mathrm{~h}$ at room temperature. The resulting solution was then neutralized with $0.5 \mathrm{M} \mathrm{NaOH}$ to $\mathrm{pH}$ 7 followed by addition of an appropriate volume of concentrated PBS to maintain the $\mathrm{pH}$ at 7.4. An aqueous solution of the peptide P18-4 in 1\% DMSO was prepared and was added to the micellar solution under constant stirring such that the P18-4:polymer molar ratio is 1:5. The solution was allowed to stir for $2 \mathrm{~h}$ after which $\mathrm{NaBH}_{3} \mathrm{CN}$ (10 eq.) was added and the reaction was stirred for $96 \mathrm{~h}$. The resulting micellar solution was dialyzed against distilled water and lyophilized.

\subsection{Characterization of synthesized block copolymers}

The number-average molecular weight of PEO-PCL and PEO-PBCL block copolymers was determined from the ${ }^{1} \mathrm{H}$ NMR spectrum of the block copolymers in $\mathrm{CDCl}_{3}(600 \mathrm{MHz}$, 
Bruker Avance III instrument, Bruker BioSpin Corporation, Billerica, MA) by comparing the peak intensity of methylene hydrogens of PEO $\left(-\mathrm{CH}_{2} \mathrm{CH}_{2} \mathrm{O}-, \delta=3.65 \mathrm{ppm}\right)$ to the hydrogens of methylene group of PCL or PBCL backbone $\left(-\mathrm{OCH}_{2^{-}}, \delta=4.05 \mathrm{ppm}\right)$, considering a $5000 \mathrm{~g} / \mathrm{mol}$ molecular weight for PEO.

The number-average molecular weight of PEO-PCL-PCC and PEO-PBCL-PCC tri-block copolymers was determined from the ${ }^{1} \mathrm{H}$ NMR spectrum of the block copolymers in $\mathrm{CDCl}_{3}$ at $600 \mathrm{MHz}$ by comparing the peak intensity of the hydrogens of PEO $\left(-\mathrm{CH}_{2} \mathrm{CH}_{2} \mathrm{O}-, \delta=3.65 \mathrm{ppm}\right)$ to the methylene hydrogens of PCC block $\left(-\mathrm{OCH}_{2^{-}}, \delta=4.75 \mathrm{ppm}\right)$, considering a $5000 \mathrm{~g} / \mathrm{mol}$ molecular weight for PEO.

The conjugation efficiency of Cy5.5 to PEO-PCL-PCC and PEO-PBCL-PCC was determined by fluorescence spectrophotometer using a SpectraMax M4 microplate reader (Molecular Devices, Sunnyvale, CA), measuring the excitation at $673 \mathrm{~nm}$ and emission at 707 $\mathrm{nm}$ as described the manufacturer. The conjugation efficiency of P18-4 peptide to acetal-PEOPCL and acetal-PEO-PBCL micelles was determined by reverse-phase HPLC according to a previously published procedure $[5,28]$.

\subsection{Preparation and characterization of block copolymer micelles}

Cy5.5-loaded PEO-PCL or PEO-PBCL block copolymer micelles were prepared through formation of mixed micelles by a co-solvent evaporation method as described previously $[8,22]$. Briefly, either PEO-PCL (18 mg) and PEO-PCL-PCC-Cy5.5 (2 mg) or PEO-PBCL (18.88 mg) and PEO-PBCL-PCC-Cy5.5 (1.12 mg) were mixed and dissolved in THF (0.4 mL). The solution was added to $4 \mathrm{~mL}$ of doubly distilled water in a drop-wise manner under moderate stirring at room temperature, followed by evaporation of THF under vacuum. The prepared micellar 
solution was then centrifuged to remove any aggregates. The concentration of Cy5.5 dye in the micelles was $0.4 \mu \mathrm{g} / \mathrm{mg}$ of the polymer.

Cy5.5-loaded PEO-PCL or PEO-PBCL block copolymer micelles with P18-4 peptide modification on their surface were prepared by co-solvent evaporation method as described above. For peptide density of $0.1 \mathrm{~mol} / \mathrm{mol}$ of the polymer, mixed micelles were prepared using either PEO-PCL (9.0 mg), P18-4-PEO-PCL (9.0 mg), and PEO-PCL-PCC-Cy5.5 (2.0 mg); or PEO-PBCL (9.4 mg), P18-4-PEO-PBCL (9.4 mg), and PEO-PBCL-PCC-Cy5.5 (1.1 mg). For peptide density of $0.2 \mathrm{~mol} / \mathrm{mol}$ of the polymer, mixed micelles were prepared using either P18-4PEO-PCL (18.0 mg), and PEO-PCL-PCC-Cy5.5 (2.0 mg); or P18-4-PEO-PBCL (18.9 mg), and PEO-PBCL-PCC-Cy5.5 (1.1 mg). Polymeric micelles with low peptide density of $0.1 \mathrm{~mol} / \mathrm{mol}$ of the polymer were termed as 10\%P18-4-PEO-PCL or 10\%P18-4-PEO-PBCL. Polymeric micelles having high peptide density of $0.2 \mathrm{~mol} / \mathrm{mol}$ of the polymer, termed as $20 \% \mathrm{P} 18-4-\mathrm{PEO}-\mathrm{PCL}$ or 20\%P18-4-PEO-PBCL. The concentration of Cy5.5 dye in the P18-4 decorated micelles was 0.4 $\mu \mathrm{g} / \mathrm{mg}$ of the polymer.

The Z-average size and size distribution of micelles were measured by dynamic light scattering (DLS) using a commercial Zetasizer Nano-ZS (Malvern Instruments, Worcestershire, UK). All DLS measurements were made at $25.0 \pm 0.1{ }^{\circ} \mathrm{C}$ with a $173^{\circ}$ scattering angle. The samples were dissolved with deionized water and centrifuged prior to analysis. For this measurement, plain PEO-PCL-PCC or PEO-PBCL-PCC were used in the preparation of micelles, instead of PEO-PCL-PCC-Cy5.5 or PEO-PBCL-PCC-Cy5.5, respectively. This is because the excitation and emission spectra of Cy5.5 would interfere with the He-Ne $633 \mathrm{~nm}$ laser of the Zetasizer Nano-ZS. 
The CMC of the polymeric micelles was determined using fluorescence spectroscopy. Briefly, solutions of Cy5.5-loaded unmodified or P18-4 decorated PEO-PCL or PEO-PBCL micelles having concentrations ranging from $400-0.2 \mu \mathrm{g} / \mathrm{mL}$ were prepared in 96-well opaque plates. The intensity of light emitted at $707 \mathrm{~nm}$ after excitation at $673 \mathrm{~nm}$ was measured by fluorescence spectroscopy at $25^{\circ} \mathrm{C}$ using a fluorescence spectrophotometer.

Kinetic stability of the micellar formulations was evaluated after incubation with a destabilizing agent, sodium dodecyl sulfate (SDS) according to previously published method [23,29]. Briefly, micellar stock solutions of PEO-PCL, PEO-PBCL, 10\%P18-4-PEO-PCL, or 10\%P18-4-PEO-PBCL having concentrations of $3 \mathrm{mg} / \mathrm{mL}$ were mixed with aqueous stock solution of SDS $(20 \mathrm{mg} / \mathrm{mL})$ at a ratio of 2:1 v/v (micelle:SDS). Samples were analyzed at predetermined time intervals by DLS for intensity distribution as well as polydispersity index (PDI).

\subsection{In vitro cell uptake study using flow cytometry}

MDA-MB-231-luc cells or MCF10A cells were seeded into 24-well plates at densities of $1 \times 10^{5}$ cells/well and incubated at $37^{\circ} \mathrm{C}$ for $24 \mathrm{~h}$ until they are $70 \%$ confluent. Free Cy5.5 and micelles of PEO-PCL, PEO-PBCL, 10\%P18-4-PEO-PCL, 10\%P18-4-PEO-PBCL, 20\%P18-4PEO-PCL, 20\%P18-4-PEO-PBCL at a concentration of $0.2 \mu \mathrm{g} / \mathrm{mL}$ of Cy5.5 (equivalent to 0.5 $\mathrm{mg} / \mathrm{mL}$ of micellar solution) were added to the wells in triplicate and incubated with cells for 4 and $24 \mathrm{~h}$ at $37^{\circ} \mathrm{C}$. For the competition experiments, MDA-MB-231-luc cells were pre-incubated with excess free p18-4 peptide $(1 \mathrm{mg} / \mathrm{mL})$ for $30 \mathrm{~min}$ and then incubated with the above mentioned formulations for $24 \mathrm{~h}$ at $37^{\circ} \mathrm{C}$ according to a previously described method [30]. After the incubation period, cells were washed three times with cold PBS and trypsinized. A 4\% 
paraformaldehyde in PBS solution was added to fix the cells and the Cy5.5 uptake was acquired on a BD FACSCalibur ${ }^{\mathrm{TM}}$ flow cytometer (BD Biosciences, Franklin Lakes, NJ). The cellassociated Cy5.5 was excited using a red-diode laser $(635 \mathrm{~nm})$ and the FL4 channel $(675 \mathrm{~nm})$ was used to detect the cell-associated fluorescence. The data was analyzed with FCS Express ${ }^{\mathrm{TM}}$ software (De Novo Software, Los Angeles, CA).

\subsection{In vitro cell uptake study using confocal microscopy}

Confocal microscopy was used to assess the uptake of conjugated Cy5.5 in different micellar formulations in MDA-MB-231-luc cells. Cells were seeded into 12-well plates containing round cover slips $(0.2 \mathrm{~mm}$ thickness $)$ at densities of $2 \times 10^{4}$ cells/well and incubated at $37{ }^{\circ} \mathrm{C}$ for $24 \mathrm{~h}$ until they are $20 \%$ confluent. Free Cy5.5 and micelles of PEO-PCL, PEO-

PBCL，10\%P18-4-PEO-PCL，10\%P18-4-PEO-PBCL, 20\%P18-4-PEO-PCL, and 20\%P18-4PEO-PBCL at a concentration of $0.2 \mu \mathrm{g} / \mathrm{mL}$ of Cy5.5 (equivalent to $0.5 \mathrm{mg} / \mathrm{mL}$ of micellar solution) were added to the wells in triplicate and incubated with cells $24 \mathrm{~h}$ at $37{ }^{\circ} \mathrm{C}$. After the incubation period, cells were washed three times with cold PBS and fixed for $10 \mathrm{~m}$ using $4 \%$ paraformaldehyde in PBS solution. The cover-slips were removed and were inverted on a slide with a drop of mounting media containing DAPI. The slides were allowed to cure in the dark for 24 h. Uptake of Cy5.5 in cells was visualized by a Zeiss LSM 710 confocal microscope (Carl Zeiss Microscope systems, Jena, Germany) using blue (Ex: 405 nm; Em: 410-500 nm) and red (Ex: $633 \mathrm{~nm}$; Em: 633-744 nm) filters with 20x magnification. The images were analyzed using Zen 2012 software (Carl Zeiss Microscope systems, Jena, Germany).

\subsection{Animal model}


Female athymic NIH-III mice were purchased from Charles River (Wilmington, MA). All experiments were performed using 4-6 week old female mice. All animal studies were conducted in accordance with the guidelines of the Canadian Council on Animal Care (CCAC) with approval from the Animal Care and Use Committee (ACUC) of the University of Alberta (Edmonton, AB, Canada). Mice were kept on the 2014S Teklad Global 14\% protein rodent maintenance diet which is low on chlorophyll to minimize fluorescence from food. To establish the orthotopic mammary fat pad tumor model, mice were randomly assigned into five groups of six mice per group. Mice were injected with $2 \times 10^{6}$ MDA-MB-231-luc cells in $50 \mu \mathrm{L}$ solution of 50\% Matrigel Basement Membrane Matrix (BD Biosciences, Franklin Lakes, NJ), into the left abdominal mammary fat pad [31]. The mice were used when the tumors reached a size of 600 $\mathrm{mm}^{3}$ (4 weeks after injection). Animals were monitored daily according to previously reported method [30].

\subsection{In vivo imaging and tissue biodistribution}

Animals were treated with micellar solutions of Cy5.5-loaded PEO-PCL, PEO-PBCL, 10\%P18-4-PEO-PCL, and 10\%P18-4-PEO-PBCL at concentrations of $250 \mathrm{mg} / \mathrm{kg}$ of body weight (equivalent to $0.1 \mathrm{mg} / \mathrm{kg}$ of free Cy5.5) [32] by IV injection through the tail vein. At various time-points of 4, 24, 48, and $72 \mathrm{~h}$, mice were imaged for fluorescence and bioluminescence using the IVIS Spectrum Preclinical In Vivo Imaging System (PerkinElmer, Waltham, MA). For in vivo fluorescence imaging, animals were imaged for $0.5 \mathrm{~s}, 10$ bin, level B at an excitation and emission wavelength of $680 \mathrm{~nm}$ and $720 \mathrm{~nm}$ respectively. Spectral unmixing was used to analyze the images and remove traces of autofluorescence. For bioluminescence 
imaging, luciferin potassium salt $(150 \mathrm{mg} / \mathrm{kg})$ in DPBS was injected sc into the loose skin on the back of the neck $15 \mathrm{~m}$ prior to imaging. Animals were imaged for $0.5 \mathrm{~s}, 10 \mathrm{bin}$, level B.

At 48 and $72 \mathrm{~h}$ time-points, three mice were randomly selected from each group and euthanized immediately after in vivo bioluminescence imaging. Tumors and other organs (liver, lung, kidneys, heart, spleen, and brain) were excised and soaked in a 12-well plate containing luciferin $(300 \mu \mathrm{g} / \mathrm{mL})$ prior to imaging. The organs were imaged for fluorescence and bioluminescence using the IVIS Spectrum Imaging System. For ex vivo fluorescence imaging, animals were imaged for $0.5 \mathrm{~s}, 10 \mathrm{bin}$, level $\mathrm{B}$ at an excitation and emission wavelength of 680 $\mathrm{nm}$ and $720 \mathrm{~nm}$ respectively. For bioluminescence imaging, animals were imaged for $0.5 \mathrm{~s}, 10$ bin, level B.

\subsection{Statistics}

Compiled data were presented as means \pm standard deviation $(\mathrm{SD})$ or mean \pm standard error (SE). Where feasible, the data were analyzed for statistical significance using unpaired student's t-test, or one-way analysis of variance (ANOVA) followed by Tukey's post-hoc test as noted in the results section. The level of significance was set at $\alpha \leq 0.05$.

\section{Results}

\subsection{Characteristics of NIR dye labeled PEO-PCL and PEO-PBCL block copolymers}

Labeling of PEO-PCL and PEO-PBCL block copolymers with NIR dye was accomplished in three steps (Scheme 1): first, PEO-PCL and PEO-PBCL were synthesized by ring-opening polymerization of $\varepsilon$-caprolactone and $\alpha$-benzyl carboxylate- $\varepsilon$-caprolactone 
monomer, respectively, in the presence of methoxy PEO [22]. The molecular weights of PEOPCL and PEO-PBCL were measured to be 6290 and 7700 g/mol, respectively, by ${ }^{1} \mathrm{H}$ NMR (Fig. S2, Supporting Information). The degree of polymerization (DP) of the core-forming block was calculated to be 11 for both PEO-PCL and PEO-PBCL (Table S1, Supporting Information). In the second step, $\alpha$-propargyl carboxylate- $\varepsilon$-caprolactone (PCC) was conjugated to the PEO-PCL and PEO-PBCL end. Conjugation of PCC to PEO-PCL or PEO-PBCL led to a decrease in DP of PCL and PBCL segments in the block copolymers from 11 to 7 . Finally, Cy5.5 azide was conjugated to the PCC end of PEO-PCL-PCC or PEO-PBCL-PCC via copper-catalyzed azidealkyne cyclo-addition (CuAAC) click chemistry reaction [33]. The average molar conjugation efficiency of Cy5.5 to the block copolymers was $56.9 \%$ and $76.1 \%$ for PEO-PCL-PCC-Cy5.5 and PEO-PBCL-PCC-Cy5.5, respectively. PEO-PBCL-PCC showed significantly higher conjugation efficiency of Cy5.5 than PEO-PCL-PCC (P < 0.05; student's $t$-test). P18-4 was successfully conjugated to the PEO end of acetal-PEO-PCL or acetal-PEO-PBCL with an average molar conjugation of $20.1 \%$ and $20.5 \%$, respectively, as confirmed by HPLC (Table S1, Scheme S3, Supporting Information) [5,34].

\subsection{Characteristics of mixed polymeric micelles without and with NIR labeling}

Cy5.5 labeled block copolymers were assembled to polymeric micelles by a co-solvent evaporation method through preparation of mixed micelles (Scheme 2) [8,22]. Mixed micelles at smilar conditions and ratios without Cy5.5 were also developed to make micelles compatiable with DLS measurements. The physicochemical characteristics of prepared mixed polymeric micelles without Cy5.5 are listed in Table 1. The average size of mixed micelles formed from PCL containing block copolymers was significantly higher $(P<0.05$; Students' $t$-test $)$ compared 
to micelles formed from PBCL containing block copolymers. Similar results were seen in the case of PDI. The average size of PEO-PBCL micelles showed a significant increase $(P<0.05$; one-way ANOVA) as the P18-4 peptide was attached and its density was increased. The increasing trend in average diameter was only observed for mixed micelles of PEO-PCL at $20 \%$ P18-4.

For NIR labeled mixed micelles, as the block copolymer forms micelles, the Cy5.5 dye enters the core thus showing a decrease in the intensity of emitted light (quenching). The concentration at which the slope of the graph of emission v/s concentration starts to decrease is termed as the critical micellar concentration (CMC). Micelles formed from PBCL containing block copolymers exhibited a 7-fold decrease in CMC when compared with those formed from PCL containing block copolymers (Table 1) similar to previous findings where a different method was used to measure CMC of similar structures [23]. Formation of mixed micelles with P18-4 modified block copolymers did not significantly change the CMC of block copolymers ( $P$ > 0.05; one-way ANOVA) irrespective of the P18-4 modified block copolymer density. Of note is that at the highest concentration of $400 \mu \mathrm{g} / \mathrm{mL}$ of the copolymers, the intensity of emitted light from all micellar systems was similar to each other $(P<0.05$; one-way ANOVA, Tukey's posthoc test) indicating that all the micellar systems had a similar quenching of the Cy5.5 dye.

PEO-PCL based micelles, unmodified or modified with 10 mol \% P18-4 peptide showed a significant decrease in the signal intensity of the micellar peak to $\sim 50$ and $\sim 21 \%$, respectively, within $24 \mathrm{~h}$ of incubation with SDS (Fig. 1). PEO-PBCL based micelles, on the other hand, whether modified with P18-4 or not, showed a signal intensity of $\geq 90 \%$ throughout the $72 \mathrm{~h}$ incubation with SDS. Hence, attachment of benzyl carboxylate to the micellar core resulted in improved stability against micellar dissociation in the presence of SDS. This was in line with 
previously published results from our lab [23]. Formation of mixed micelles with P18-4 modified PEO-PCL or PEO-PBCL, however, led to a decrease in the stability of the micelles against dissociation.

Scheme 1. Synthetic scheme for the preparation of Cy5.5-labeled polymeric micelles.<smiles>[R]C(CCCCOC)C(=O)OCCOC</smiles><smiles>C=CCOC(=O)C1CCCCCC1COCCOCCOCCO</smiles>
PEO-PBCL MN

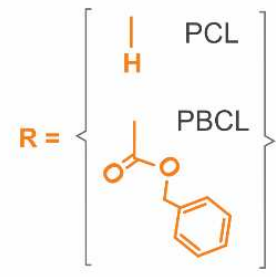<smiles>[R]C(CCCCOC([2H])C(=O)C(CCCCO)C(=O)OCC=C)C(=O)OCCC(C)OC</smiles>

PEO-PCL-PCC PEO-PBCL-PCC Mre

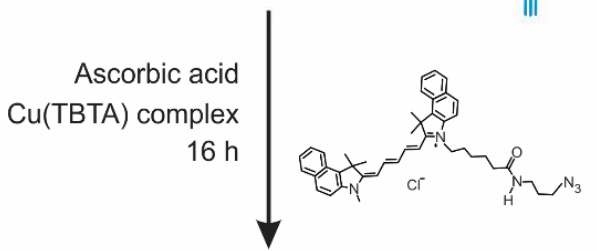

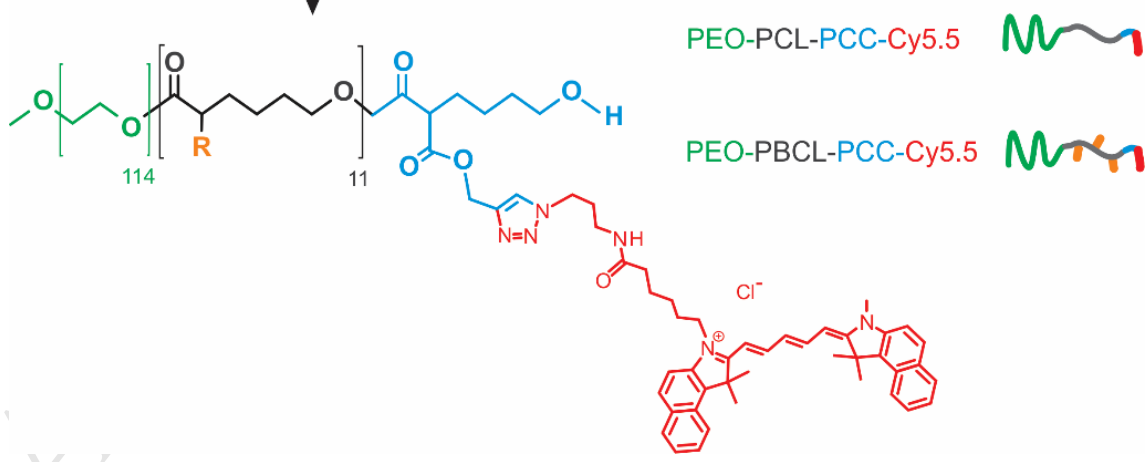


Scheme 2. Combination of block copolymer for preparing the Cy5.5 labeled mixed micelles.

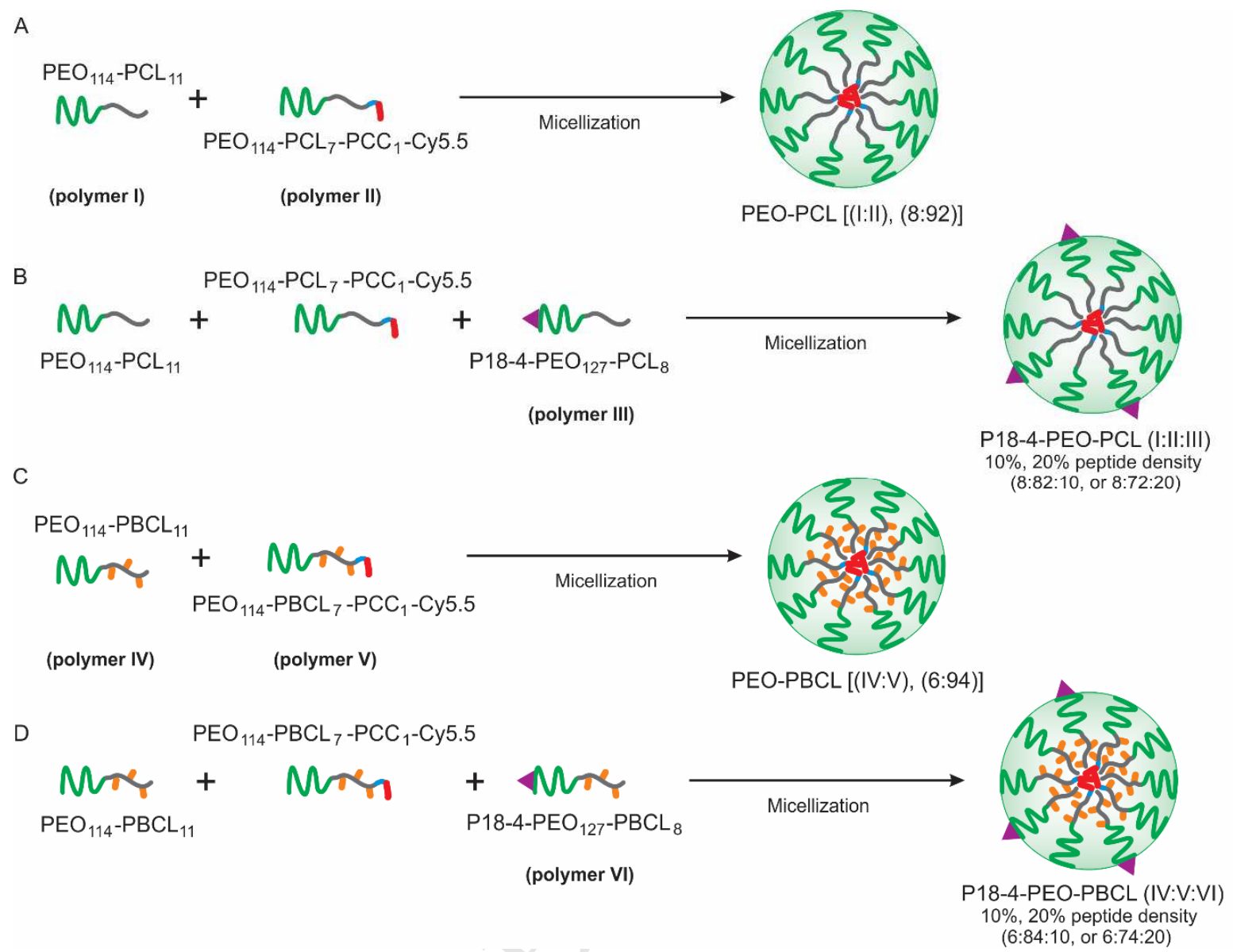


Table 1. Characteristics of prepared mixed block copolymer micelles.

\begin{tabular}{ccccc}
\hline $\begin{array}{c}\text { Polymeric } \\
\text { Micelles }^{a}\end{array}$ & $\begin{array}{c}\text { P18-4 density } \\
(\mathrm{mol} / \mathrm{mol})^{b}\end{array}$ & $\begin{array}{c}\text { Z-Average micellar } \\
\text { size } \pm \mathrm{SD}(\mathrm{nm})^{c}\end{array}$ & ${\text { PDI } \pm \mathrm{SD}^{d}}$ & ${\mathrm{CMC} \pm \mathrm{SD}(\mu \mathrm{M})^{e}}^{{ }^{c}}$ \\
\hline PEO-PCL (I:II) & - & $148.5 \pm 13.6$ & $0.499 \pm 0.051$ & $3.40 \pm 0.28$ \\
PEO-PBCL (IV:V) & - & $30.2 \pm 0.4 *$ & $0.184 \pm 0.009 *$ & $0.49 \pm 0.07 *$ \\
10\%P18-4-PEO-PCL (I:II:III) & 0.1 & $110.0 \pm 11.8$ & $0.831 \pm 0.158$ & $3.71 \pm 0.39$ \\
10\%P18-4-PEO-PBCL (IV:V:VI) & 0.1 & $40.4 \pm 0.4 *$ & $0.302 \pm 0.019 *$ & $0.77 \pm 0.02 *$ \\
20\%P18-4-PEO-PCL (I:II:III) & 0.2 & $318.4 \pm 89.7$ & $0.422 \pm 0.063$ & $4.22 \pm 0.73$ \\
20\%P18-4-PEO-PBCL (IV:V:VI) & 0.2 & $52.2 \pm 0.8 *$ & $0.293 \pm 0.022^{*}$ & $1.18 \pm 0.40 *$ \\
\hline
\end{tabular}

${ }^{a}$ The number shown in the parentheses indicates the combination of block copolymers used in mixed micelles (see Scheme 2).

${ }^{b}$ Density of peptide in polymeric micelles expressed as the mole of peptide per mole of polymer.

${ }^{c}$ Z-Average micellar size estimated by DLS technique $(n=3)$.

${ }^{d}$ Average polydispersity index (PDI) of micellar size distribution $(n=3)$.

${ }^{e}$ Measured from the onset of a decrease in the slope of the intensity of emission of Cy5.5 as a function of block copolymer concentration $(n=3)$.

${ }^{*}$ Significantly different from its counterpart micelle containing PCL $(P<0.05$; Student's $t$-test $)$.

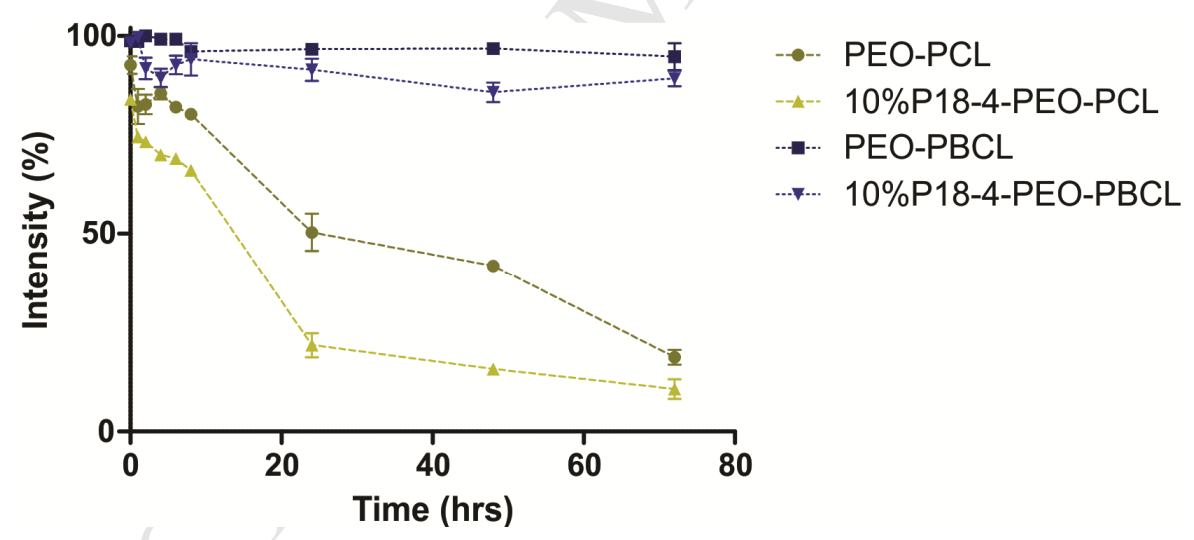

Fig. 1. Characteristics of prepared mixed micelles. The percentage intensity of micellar peak $(2 \mathrm{mg} / \mathrm{mL}) \mathrm{as} \mathrm{a}$ function of time in the presence of SDS $(6.7 \mathrm{mg} / \mathrm{mL})$. Each point represents mean $\pm \operatorname{SD}(n=3)$. 


\subsection{In vitro uptake by breast cancer versus normal cells}

As seen in Fig. 2, the fluorescent signal for peptide-modified PEO-PCL and PEO-PBCL micelles in MDA-MB-231-luc breast cancer cells was higher than that for plain micelles particularly after $24 \mathrm{~h}$ incubation $(P<0.05$; Students' $t$-test). At this incubation time, PEO-PCL and PEO-PBCL micelles presenting 10 mol \% of P18-4 peptide demonstrated 1.7- and 1.3-fold greater breast cancer cell associated fluorescence (Fig. 2A) than unmodified micelles, respectively. In the case of PEO-PCL and PEO-PBCL micelles presenting 20 mol \% of P18-4 peptide, cellular association increased by 2.0 - and 1.2-fold, when compared to unmodified micelles, respectively. The unmodified PEO-PCL and PEO-PBCL micelles showed similar cell associated fluorescence ( $P>0.05$; Students' $t$-test) at $4 \mathrm{~h}$. However, PEO-PCL micelles exhibited a significantly higher cell associated fluorescence than PEO-PBCL ones at $24 \mathrm{~h}(P<0.05$; unpaired students' $t$-test). 
A

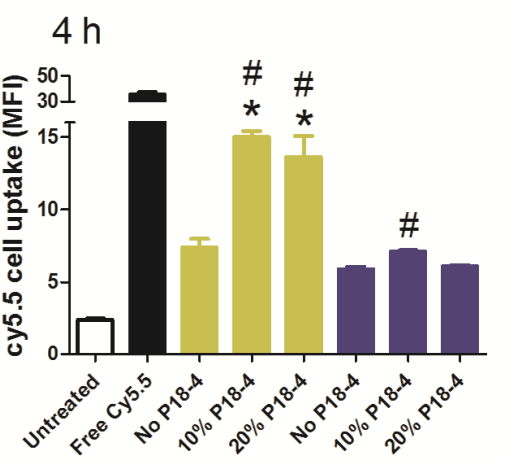

$24 \mathrm{~h}$

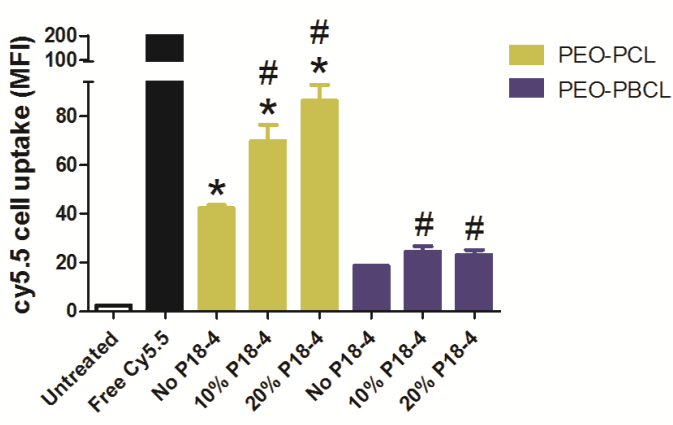

B

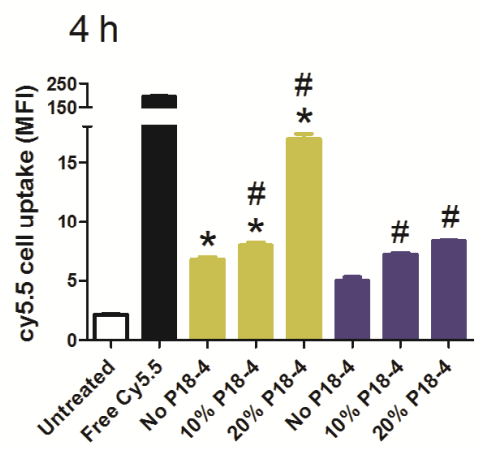

$24 \mathrm{~h}$

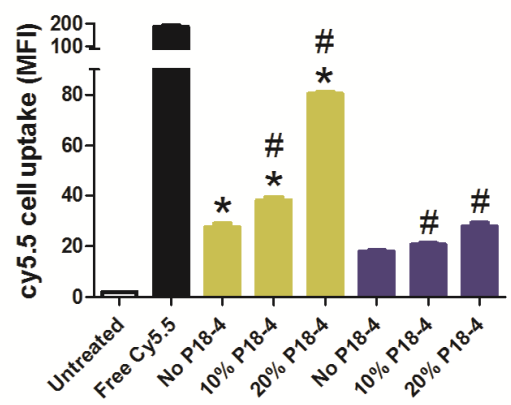

C

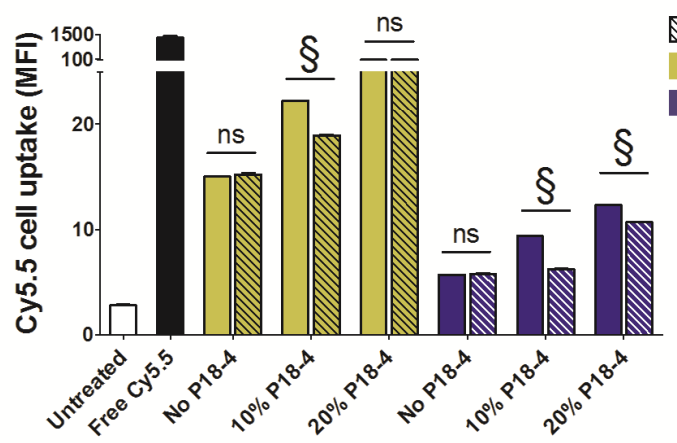

Fig. 2. Cellular association of Cy5.5-labeled micelles by MDA-MB-231-luc (A), and MCF10A (B) cells. The bar graphs show the mean fluorescence intensity (MFI) of the cells after 4 and $24 \mathrm{~h}$ incubation. This experiment was also done with and without competition (pre-treatment using excess of free P18-4) using MDA-MB-231-luc cells after $24 \mathrm{~h}$ incubation (C). The data are presented as mean \pm SE $(n=3)$. *: Significant difference between PEO-PCL and PEO-PBCL (with or without peptide on their surface). \#: Significant difference between PEO-PCL and P18-4PEO-PCL, or PEO-PBCL and P18-4-PEO-PBCL. §: Significant difference from the competition group after preincubation with excess free peptide ( $P<0.05$; unpaired Students' $t$-test). 
The uptake of Cy5.5-loaded polymeric micelles was also determined in MCF10A mammary epithelial cells as seen in Fig. 2B. In the case of MCF10A cells, after $24 \mathrm{~h}$ incubation, PEO-PCL and PEO-PBCL micelles presenting 10 mol \% of P18-4 peptide demonstrated 1.4- and 1.1-fold greater cellular association than unmodified micelles, respectively. This was lower than the cellular association seen by these micelles in MDA-MB-231-luc breast cancer cells. However, in the case of PEO-PCL and PEO-PBCL micelles presenting 20 mol \% of P18-4 peptide, MCF10A cellular association increased by 2.9-fold and 1.6-fold, respectively, which was more than 2.0-fold and 1.2-fold, seen in the breast cancer cells (Fig. 2A). This indicated a higher non-specific cellular association for PEO-PCL and PEO-PBCL micelles modified with 20 mol \% of P18-4 peptide.

To explore whether the increased cell association in MDA-MB-231-luc cells is due to the presence of receptor for the P18-4 peptide, competition study was carried out, in which cells were pre-treated with excess P18-4 peptide before incubating the cells for $24 \mathrm{~h}$ with PCL and PBCL based micellar formulations. As seen in Fig. 2C, the presence of excess free P18-4 peptide significantly reduced the cellular association of PEO-PCL and PEO-PBCL micelles presenting 10 mol \% of P18-4 peptide $(P<0.05$; unpaired students' $t$-test $)$. However, the presence of excess free P18-4 peptide did not affect the cellular association of PEO-PCL micelles presenting 20 mol \% of P18-4 peptides. For PEO-PBCL micelles at this level of peptide conjugation, still competition with free peptide was observed.

The uptake of Cy5.5-labeled polymeric micelles was determined by MDA-MB-231-luc breast cancer cells using confocal microscopy after $24 \mathrm{~h}$ incubation. As seen in Fig. 3, peptide modification increased intracellular fluorescence of labeled PEO-PCL and PEO-PBCL micelles in the cytoplasm. Both PEO-PCL and PEO-PBCL micelles presenting 20 mol \% of P18-4 
peptide, showed strong fluorescence in cells when compared with their unmodified counterparts or counterparts presenting 10 mol \% of P18-4 peptide. Also, PEO-PCL micelles, with or without P18-4 modification showed stronger Cy5.5 fluorescence in cells when compared to PEO-PBCL micelles. These observations were in accordance with our past findings and data from cellular association studies (Fig. 2). 


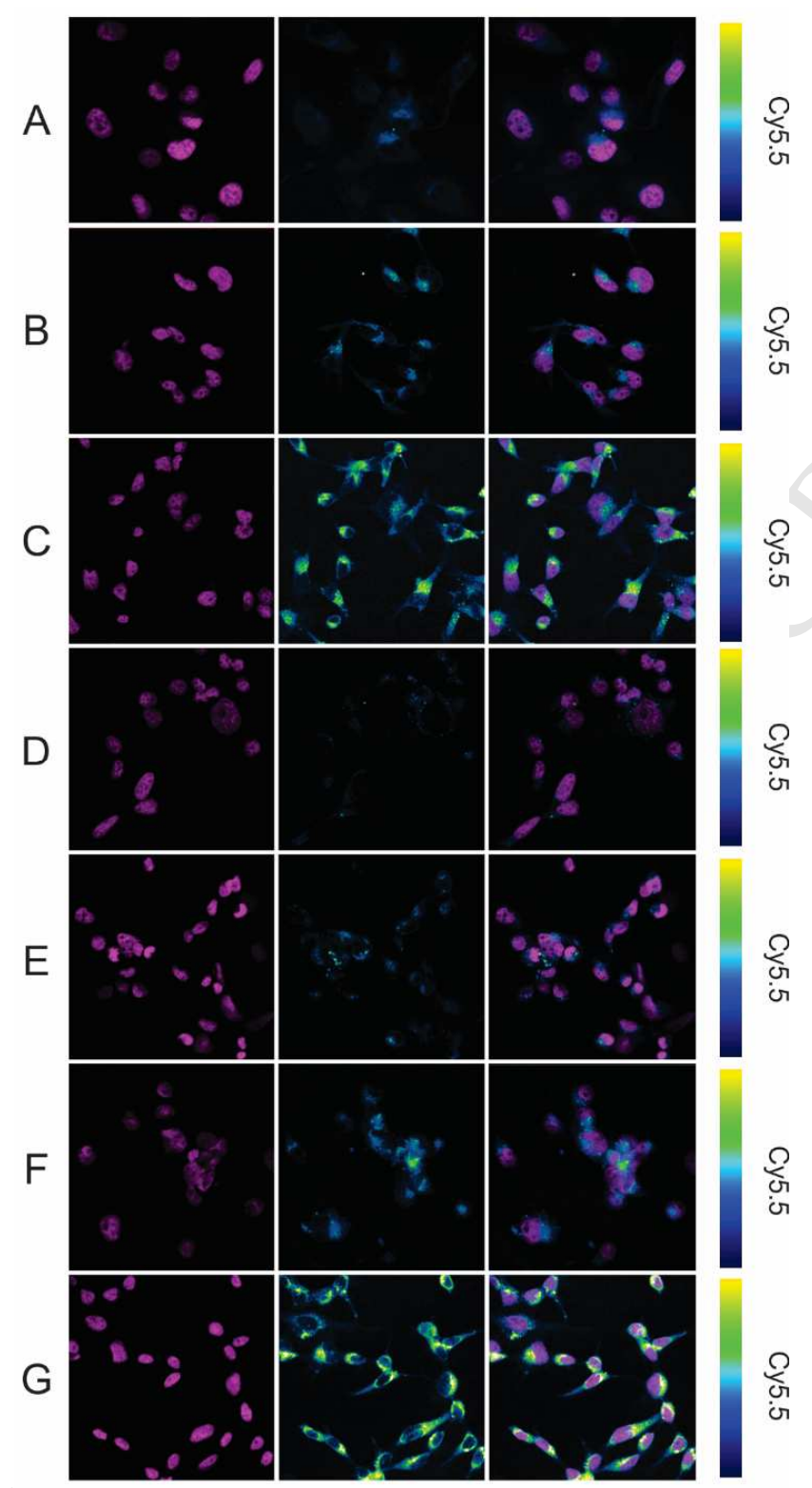

Fig. 3. Cellular uptake of Cy5.5-labeled micelles with different polymer compositions: PEO-PCL (A), 10\%P18-4PEO-PCL (B), 20\%P18-4-PEO-PCL (C), PEO-PBCL (D), 10\%P18-4-PEO-PBCL (E), 20\%P18-4-PEO-PBCL (F), and free Cy5.5 (G), in MDA-MB-231-luc cells using confocal microscopy after $24 \mathrm{~h}$ incubation. Images represent nuclear stain DAPI (pink) alone, Cy5.5 (blue-yellow) alone, and the merged dyes. 


\subsection{Imaging of Cy5.5 labeled micelles in orthotopic breast cancer mouse model}

The bioluminescence signal can be seen at the sight of injection (Fig. 4F) i.e. left mammary fat pad, indicating successful generation of primary breast tumor at its natural location. The imaging studies (Fig. 4) showed, upon intravenous injection, plain PEO-PCL micelles, started accumulating in the liver, tumor, and neck (presumably the cervical lymph nodes) within $4 \mathrm{~h}$ post-injection. After $24 \mathrm{~h}$, these micelles started showing higher accumulation in tumor along with increased accumulation in liver and neck. Dorsal images showed uptake of plain PEO-PCL micelles in the kidneys and spleen. Peptide modified PEO-PCL micelles had similar patterns of distribution except that they only showed uptake in kidneys upon dorsal assessment and no accumulation in spleen. Similar results were seen for the ventral images after $48 \mathrm{~h}$, with decrease in fluorescence in both liver and tumors $72 \mathrm{~h}$ post-injection. Dorsal images presented increased fluorescence in kidneys for both PEO-PCL micelles at $48 \mathrm{~h}$ and $72 \mathrm{~h}$, which perhaps points to the elimination of PEO-PCL polymers from this organ at later time points.

In the case of PEO-PBCL micelles, unmodified micelles accumulated primarily in the tumor with strong fluorescence signals throughout the body whereas PEO-PBCL micelles modified with 10 mol \% P18-4 peptide showed uptake primarily in the tumor with weak fluorescent signals throughout the body, $4 \mathrm{~h}$ post-injection. After $24 \mathrm{~h}$ post-injection, ventral images showed unmodified PEO-PBCL micelles primarily in the tumor with weaker fluorescence signals throughout the body. In the case of PEO-PBCL micelles modified with P184 peptide, fluorescent signals were primarily at the tumor site. Ventral images at 48 and $72 \mathrm{~h}$ for both, unmodified and 10 mol \% P18-4 peptide modified PEO-PBCL micelles, showed similar results of strong fluorescent signals primarily from the tumor site. Dorsal images at 24,48 , and 
$72 \mathrm{~h}$ time-points showed strong fluorescent signals from the tumor site at exact locations that are seen in the dorsal images of bioluminescence (Fig. S5, Supporting Information).

Comparing the average radiant efficiency in the tumor from the in vivo images, revealed P18-4 modified micelles to exhibit higher accumulation in the tumor at the earlier time-points. In the case of PEO-PCL micelles, P18-4 modified micelles had a significantly higher accumulation in the tumor site $4 \mathrm{~h}$ after injection when compared to their unmodified counterparts $(P<0.05$; Student's $t$-test). At later time-points, the average radiant efficiency significantly decreased and was similar for both plain and P18-4 modified PEO-PCL micelles. This decrease in the fluorescent intensity may be due to clearance by the kidneys and liver as seen in Fig. 4.

In the case of PEO-PBCL micelles, P18-4 modified micelles presented a significantly higher accumulation in the tumor site 4 and $24 \mathrm{~h}$ after injection when compared to their unmodified counterparts $(P<0.05$; Student's $t$-test $)$. For P18-4 modified PEO-PBCL micelles, the average radiant efficiency in the tumor reached maximum at 24 and $48 \mathrm{~h}$ post-injection after which it started to decrease by $72 \mathrm{~h}$. In the case of plain PEO-PBCL micelles, the average radiant efficiency shows an increasing trend from $4-72 \mathrm{~h}$ reaching a value similar to the maximum average radiant efficiency of P18-4 modified PEO-PBCL micelles, only after $72 \mathrm{~h}$. 

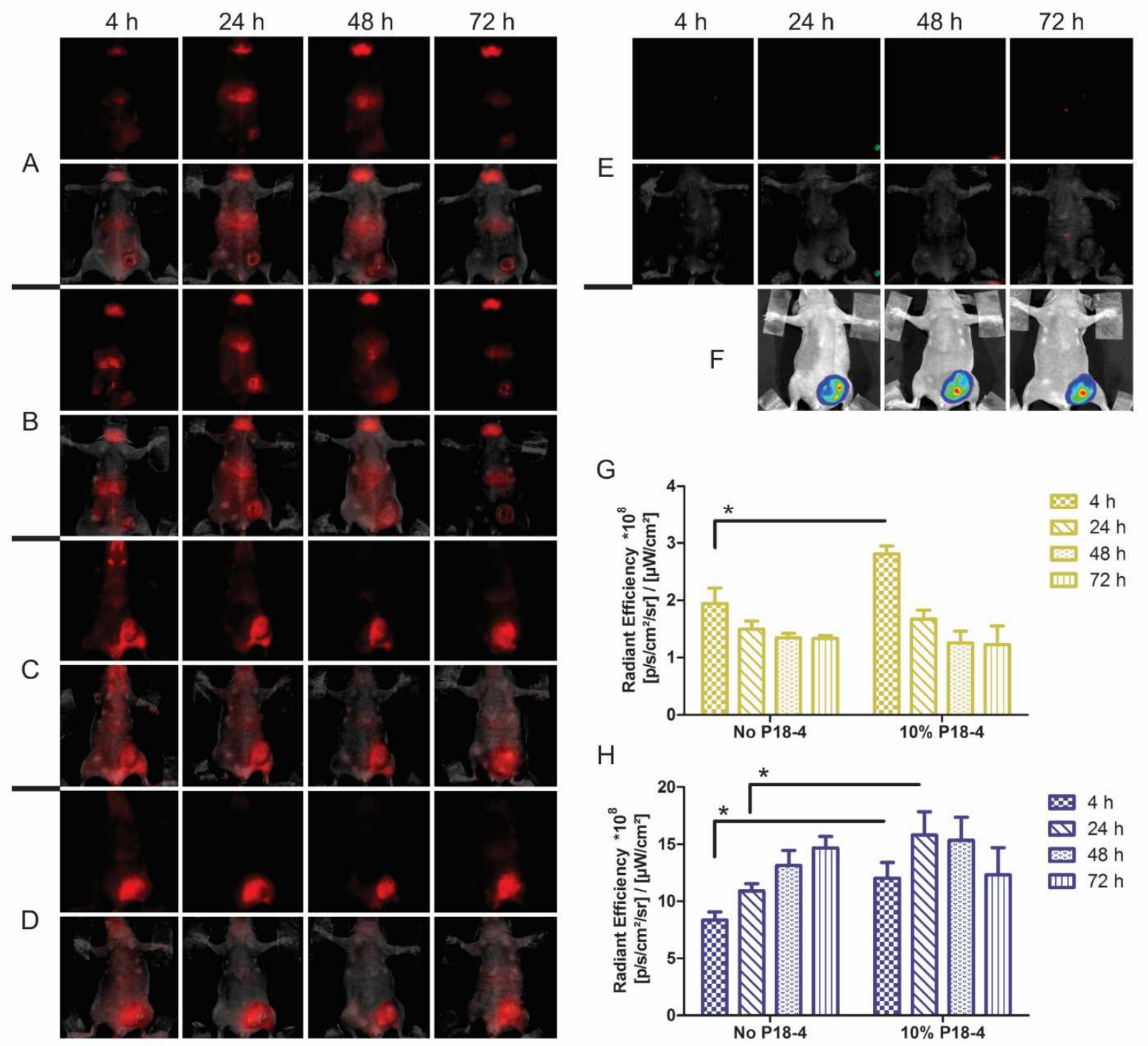

Fig. 4. In vivo NIR imaging of Cy5.5-labeled micelles composed of different polymers: PEO-PCL (A), 10\%P18-4PEO-PCL (B), PEO-PBCL (C), and 10\%P18-4-PEO-PBCL (D), and untreated (E) at 4, 24, 48, and $72 \mathrm{~h}$ after intravenous administration. Images show mice in the ventral position. Each time-point represents image of one representative mouse from a group of six mice. Images in (F) show the bioluminescence signals from MDA-MB231-luc cells. Each time-point represents image of one representative mouse in the groups. The bar graphs represent the average radiant efficiency in tumor of plain and P18-4 modified PEO-PCL (G), and PEO-PBCL (H) micelles at 4, 24, 48, and $72 \mathrm{~h}$ after intravenous administration. *Significantly different from its plain counterpart $(P<0.05$, unpaired Students' $t$-test). 
Fluorescence from Cy5.5 was used to image the biodistribution of PEO-PCL and PEOPBCL micelles ex vivo in different organs from animals euthanized at 48 and $72 \mathrm{~h}$ after micellar tail vein injection. As seen in Fig. 5B, both plain and P18-4 peptide modified PEO-PCL micelles, showed increased fluorescence primarily in the kidneys indicating clearance through kidneys within $72 \mathrm{~h}$. This was similar to the results seen during in vivo imaging (Fig. 4B). Both plain and peptide modified PEO-PBCL micelles, on the other hand, showed increased fluorescence signals in the liver and tumors. The average radiant efficiency of the tumor was significantly higher for plain and P18-4 modified PEO-PBCL micelles when compared with their PEO-PCL micelle counterparts $(P<0.05$; one-way ANOVA). P18-4 modification; however, did not significantly increase the average radiant efficiency of the tumor at both 48 and $72 \mathrm{~h}$ when compared to plain PEO-PCL and PEO-PBCL micelles. This was similar to the results of 48 and $72 \mathrm{~h}$ readings in in vivo images (Fig. 4C). PEO-PBCL micelles, whether unmodified or modified with P18-4 peptide, showed a significantly higher average radiant efficiency in heart, liver, lung, and spleen, and a significantly lower average radiant efficiency in kidney when compared with their PEO-PCL counterparts at $48 \mathrm{~h}$ time-point $(P<0.05$; one-way ANOVA). The higher average radiant efficiency in the kidneys indicated faster clearance for PEO-PCL micelles. Similar results were also seen after $72 \mathrm{~h}$, but were not statistically significant for some groups. P18-4 modification did not significantly change the average radiant efficiency in most organs other than the tumor when compared to plain micelles $(P>0.05$; one-way ANOVA) except for spleen and heart. P18-4 modified PEO-PBCL micelles had a reduced radiant efficiency at 48 and $72 \mathrm{~h}$ in spleen and P18-4 modified PEO-PCL micelles had a reduced radiant efficiency at $48 \mathrm{~h}$ in heart when compared to their unmodified counterpart. Although the average radiant efficiency can be used to compare the distribution in any organ amongst different groups, it is not advisable 
to use this measure to compare the distribution of NIR label between different organs. This is because of the attenuation effect of hemoglobin on NIR emission and presence of hemoglobin at different quantities in different organs [35]. 

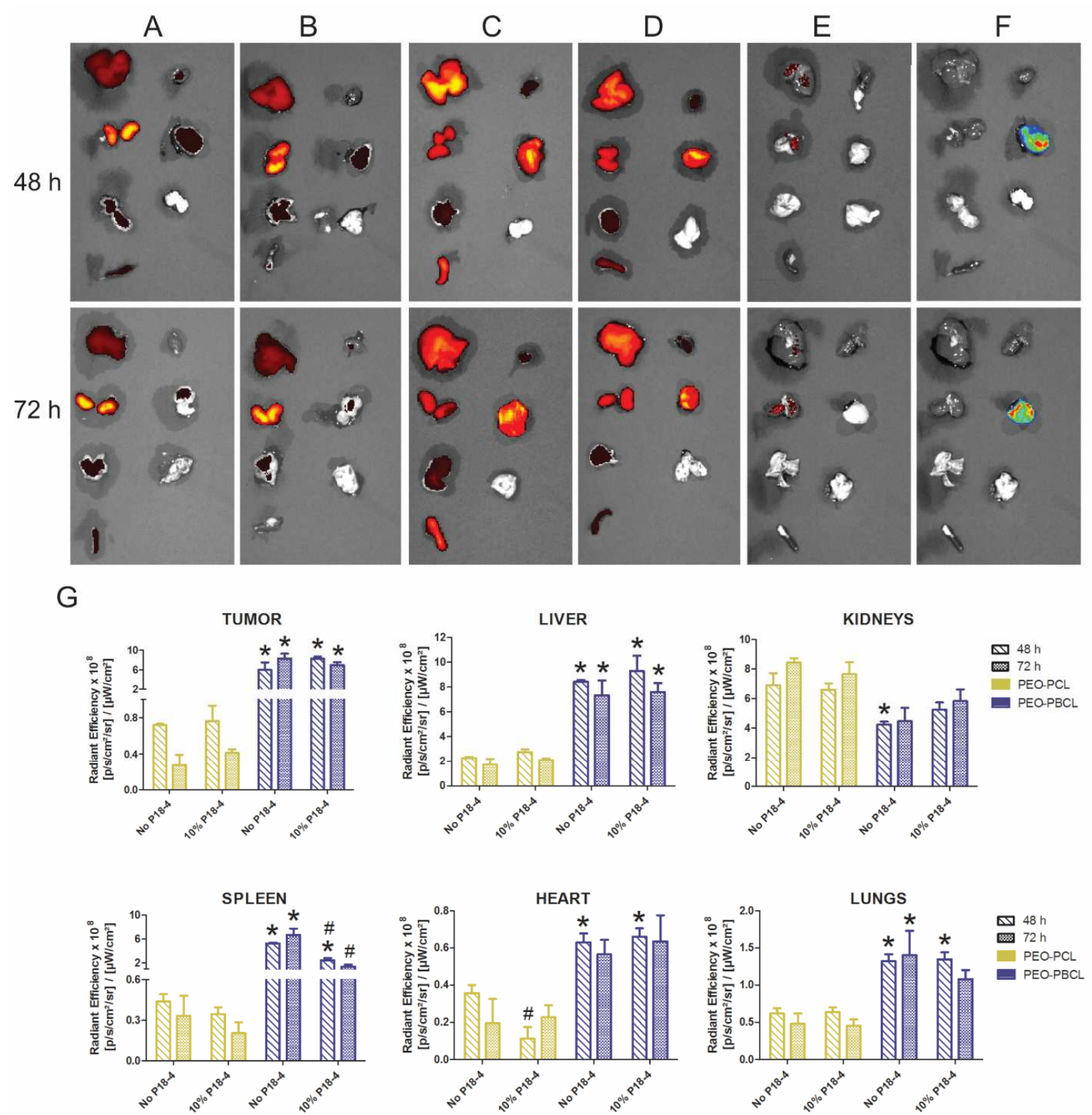

Fig. 5. Ex vivo NIR imaging of Cy5.5-labeled micelles composed of different polymers: PEO-PCL (A), 10\%P18-4PEO-PCL (B), PEO-PBCL (C), and 10\%P18-4-PEO-PBCL (D), untreated (E), and bioluminescence signal (F) at 48 and $72 \mathrm{~h}$ after intravenous administration. Images show (counter clockwise from top left corner) liver, kidneys, lungs, spleen, brain, tumor, and heart. Each time-point represents image of one mouse from the group. The graphs at the bottom $(\mathrm{G})$ represent the average radiant efficiency of cy5.5 fluorescence in tumor, liver, kidneys, spleen, heart, and lungs at 48 and $72 \mathrm{~h}$ after intravenous administration. *Significant difference between PEO-PCL and PEOPBCL (with or without peptide on their surface). \#Significant difference between PEO-PCL and P18-4-PEO-PCL, or PEO-PBCL and P18-4-PEO-PBCL $(P<0.05$; unpaired Students' $t$-test). 


\section{Discussion}

The main objective of our study was to develop traceable polymeric micellar carriers that can be used to investigate the effect of modifications in the micellar core and shell structure on their in vivo biodistribution. For this purpose, we have chemically conjugated the near infra-red (NIR) probe Cy5.5, to the hydrophobic block of PEO-PCL and PEO-PBCL. The surface of both nanocarriers were also modified with a novel breast cancer targeting peptide ligand developed by our research group in previous studies [25]. The effect of core/ and shell modifications on the micellar physicochemical properties, in vitro cancer cell specificity, and in vivo biodistribution in mice bearing orthotopic MDA-MB-231 breast tumors was then assessed.

NIR dyes are suitable for optical imaging in live animals enabling deeper tissue imaging [5,6]. In polymeric micelles, the NIR probes can either be conjugated to the hydrophilic shell of the micellar system [21], or encapsulated [36] or conjugated [5,37] to the hydrophobic core [7,38]. Conjugation of NIR probes to the micellar surface can change the interaction of the nanocarrier with proteins from the complement system, thus leading to their early removal through reticuloendothelial system recognition. It can also affect the interaction of nanocarriers with other non-specific normal cells upon encounter. Physical encapsulation of NIR probes into the core of micelles on the other hand, cannot guarantee the detainment of the NIR probe within the carrier under sink in vivo condition. To the best of our knowledge, this is the first report on the development of traceable PEO-PCL and PEO-PBCL micelles through chemical conjugation of NIR dye to the poly(ester) core of these nanocarriers and their tumor targeting ligand modified counterparts. Conjugation of NIR dyes to the poly(ester) structures is particularly challenging due to the unstable nature of the poly(ester) bonds under the required harsh chemical reaction 
conditions. In this study, cy5.5 was selected as the NIR dye because it is widely used in literature for tracking of nanocarriers and is available with various functional groups that enable multiple types of chemical conjugations. However, from a clinical perspective, other FDA approved dyes such as indocyanine green might be preferable due to its excitation and emission $>780 \mathrm{~nm}$ at which wavelength there is no interference due to tissue autofluorescence, and heamoglobin.

The experiments were conducted using PEO-PCL and PEO-PBCL micelles with similar DP (8-11) for the $\varepsilon$-caprolactone and $\alpha$-benzyl carboxylate- $\varepsilon$-caprolactone monomers and the PEO ( 5,000 Da) was used as the macro-initiator for their polymerization. The DP values were chosen to be uniform for the core-forming block in both polymers to eliminate the possibility of differences in our observations due to the hydrophobic block length. The Cy5.5 labeled PEOPCL and PEO-PBCL polymers were then mixed with either plain or P18-4 modified PEO-PCL or PEO-PBCL polymers, respectively, to achieve NIR labeled micelles (Scheme 1). Mixed PEOPCL micelles showed a significantly larger average size $(\geq 100 \mathrm{~nm})$ and PDI compared to their PEO-PBCL counterparts ( $50 \mathrm{~nm}$ ) (Table 1, Fig. S4, Supporting Information). The decrease in the size of PEO-PBCL micelles when compared to PEO-PCL micelles may be due to the ability of PEO-PBCL to form $\pi-\pi$ stacking interactions which may enable better packing of the micelles. The decrease in PDI of PEO-PBCL micelles is also an indication of the improved physicochemical stability of these micelles comapred to PEO-PCL micelles [23].

In line with our previous findings [23], we have seen a higher thermodynamic stability for PEO-PBCL based micelles compared to PEO-PCL ones as evidenced by lower CMC of PEO-PBCL micelles at similar length of the block copolymers (Table 1). The high thermodynamic stability of the polymeric micelles is an important factor determining the 
stability of polymeric micelles in the biological system [39]. Presence of aromatic groups on the PCL block also led to an increase in the kinetic stability as measured by a decrease in the rate of dissociation of micelles when incubated with SDS (Fig. 1). This may be due to the $\pi-\pi$ stacking of the benzyl carboxylate groups in PEO-PBCL micelles leading to resistance towards dissociation [23].

P18-4 is a stable decapeptide having the amino acid sequence WxEAAYQrFL (lower case letter denotes D-amino acid; $X$ is norleucine) and a molecular weight of $1296 \mathrm{Da}$. The peptide is shown to have a high affinity for breast cancer cells compared to noncancerous cells. This peptide is believed to interact with Keratin-1 on breast cancer cells [40]. Formation of mixed micelles with P18-4 modified polymers did not affect the thermodynamic stability of micelles, but decreased their kinetic stability in the presence of SDS. Pre-treatment of cells with free P18-4 peptide, resulted in a reduction in the uptake P18-4 modified micelles in MDA-MB231 breast cancer cells to the level seen for the unmodified micelles (Fig. 2C). This indicates that the P18-4 modified polymeric micelles are taken up through receptor mediated endocytosis [25,41]. Increasing the P18-4 density significantly increased the cellular uptake of Cy5.5-loaded micelles in MDA-MB-231 cells (Fig. 2 and Fig. 3). These results are in agreement with those reported by us for P18-4 modified liposomes and p160 modified micelles [30,42]. At higher peptide density of 20 mole $\%$, presence of free P18-4 peptide did not affect the uptake of P18-4 modified PEO-PCL and PEO-PBCL micelles. Besides, our results have shown higher uptake of micelles presenting high P18-4 density ( $20 \mathrm{~mol} \%$ ) by MCF10A normal cells which suggest the possibility of non-specific cell uptake. Similar results were also seen previously for high density P18-4 modified liposomes in MCF10A cells [30]. In contrast, micelles modified at 10 mol \% with P18-4 were more specifically associated with MDA-MB-231 compared to MCF10A cells. 
This is in line with previous reports which have shown the P18-4 peptide to have higher specificity for cancer cells and at the same time be internalized by these cells [25].

Micelles formed from PEO-PCL showed significantly higher uptake in MDA-MB-231 breast cancer cells compared to the ones composed of PEO-PBCL [43]. The lower thermodynamic and kinetic stability of PEO-PCL micelles might have led to their dissociation inside the cell, thus de-quenching the Cy5.5 dye, showing higher fluorescence when compared to PEO-PBCL micelles. In addition to MFI, an increase in the \% Cy5.5 positive cells for PEO-PCL micelles when compared to PEO-PBCL micelles has also been observed.

In vivo biodistribution studies were carried out in an orthotopic breast tumor animal model [44]. It is known that the response to drugs can be highly varied depending on the site of the tumor. For instance, doxorubicin could inhibit $80 \%$ of the tumor growth in an in vivo xenograft model, whereas only $40 \%$ drug activity was found in tumors at the orthotopic site [45]. Thus, orthotopic models are necessary for a more accurate analysis of tumor growth and treatment. To follow the growth of the tumor and also track any possible metastasis, MDA-MB231 cells expressing firefly luciferase were used.

Both PEO-PCL and PEO-PBCL micelles showed fluorescence in liver, spleen, and kidneys indicating their recognition by the major organs of RES along with renal clearance in kidney, respectively (Fig. 5). Plain and P18-4 modified PEO-PCL micelles presented higher accumulation in kidneys indicating faster renal clearance compared to their PEO-PBCL counterparts. Glomerular filtration, which is the first step in renal clearance, is highly sizeselective. The PEO-PCL micelles had a size of $\geq 100 \mathrm{~nm}$ which is higher than the threshold for renal clearance [46]. It is; therefore, most likely that the PEO-PCL micelles dissociated in the 
serum leading to their faster clearance. In line with this assumption, PEO-PCL micelles have shown lower in vitro thermodynamic and kinetic stability compared to PEO-PBCL micelles [43].

PEO-PBCL micelles were shown to be more stable than PEO-PCL ones and accordingly presented higher tumor accumulation than the PEO-PCL ones. However, in addition to the tumor, PEO-PBCL micelles had significantly higher accumulation in heart, liver, lungs, and spleen, but lower accumulation in the kidneys, when compared to PEO-PCL micelles (Fig. 5). The higher accumulation into the other organs may simply be a reflection of less elimination of PEO-PBCL micelles through the kidneys and their higher retention in the blood compared to PEO-PCL micelles.

The micelles may further be developed for encapsulation of anti-cancer drugs and used as theranostics for the simultaneous delivery of drug to tumor site and following the progress of disease, at the same time. The thermodynamic and kinetic stability of the nanocarrier, however, may be influenced by the encap9sulated drug. This may impact the extent and kinetics of micellar distribution in different organs, as well.

P18-4 modification resulted in more rapid accumulation of micelles in the tumor site. At later time points (> $4 \mathrm{~h}$ for P18-4 modified PEO-PCL and > $24 \mathrm{~h}$ for P18-4 modified PEO-PCL) no significant difference in tumor accumulation of P18-4 modified mixed micelles versus plain micelles was noted, however. Previous studies using RGD modified nanocarriers has reported similar results, although the receptor for RGD peptide is also over-expressed in the tumor endothelium and the rapid accumulation for the RGD modified carriers may be due to the uptake of these targeted nanocarriers in the tumor endothelium rather than due to retention in the tumor cells [47]. Unlike RGD peptide, the receptor for P18-4 is shown to be majorly expressed by tumor cells rather than angiogenic endothelium increasing the chance of retention by tumor cells 
for P18-4 modified micelles. The longer effect of peptide in tumor accumulation of PEO-PBCL may also be a reflection of higher stability and slower dissociation and separation of peptide conjugated polymers from these nano-carriers.

Interestingly, P18-4 modified PEO-PBCL micelles showed lower accumulation in the spleen, while P18-4 modified PEO-PCL micelles showed lower accumulation in heart at $48 \mathrm{~h}$ when compared to the corresponding micellar constructions without the peptide. Previous studies have demonstrated that high densities of peptides on the nanocarrier surface can lead to an abnormal uptake by the RES organs like spleen and liver resulting in faster clearance from the body $[48,49]$. Therefore the 10 mole $\%$ density of P18-4 micelles may be considered appropriate.

\section{Conclusion}

In general, lableing of PEO-poly(ester) micelles through chemical conjugation of NIR probe Cy5.5 to their poly(ester) core, provided means for following the fate of PEO-poly(ester) micelles both in vitro and in live animals facilitating discovery of structure activity relationships with respect to the biodistribution and targeting capabilities of these nano-carries. In this study, the highly stable PEO-PBCL micelles showed exteded residence time and higher levels at breast tumor follwoing intravenous administartion in tumor bearing mice, perhaps due to theattenuated dissociation and renal elimination of PEO-PBCL over PEO-PCL micelles. PEO-PBCL micelles, however, showed higher distribution to RES organs. Surface modification of both nanocarriers with the novel P18-4 peptide resulted in their higher and more specific uptake by breast cancer cells in vitro and rapid accumulation at the tumor site, in vivo. 
The results of this study demonstrated the tremendous potential of developed traceable nanocarriers, and their P18-4 modified counterparts for further advancement to image-able targeted therapy tools for breast cancer. The results also shed light on the structural characteristics of block copolymers that can be used to optimize the kinetics and extent of tumor distribution for PEO-PCL based micelles.

\section{Acknowledgements}

This study was supported by a grant from the Canadian Institute of Health Research (CIHR). S.M.G. was supported by the Alberta Innovates Health Solutions Graduate Studentship and the Honorary Dissertation Fellowship. We acknowledge Coordination for the Improvement of Higher Education Personnel (CAPES) for providing the scholarship (\# 13129139) for I.M.P. We thank Mr. Vishwanatha Somayaji, Faculty of Pharmacy and Pharmaceutical Sciences, University of Alberta for assistance with ${ }^{1} \mathrm{H}$ NMR analysis; the Flow Cytometry Lab in the Department of Experimental Oncology at Cross Cancer Institute for assistance with flow cytometry; the Microscopy Lab in Department of Experimental Oncology at Cross Cancer Institute for assistance with confocal microscopy; the Advanced Microscopy Facility (AMF), Department of Biological Sciences, University of Alberta for assistance with TEM analysis; Mr. Dan McGinn, Department of Oncology, University of Alberta, for assistance with i.v. (tail-vein) injections; and Ms. Nicole Favis, Department of Immunology, University of Alberta for assistance with the animal facility. 


\section{References}

[1] I. Brigger, C. Dubernet, P. Couvreur, Nanoparticles in cancer therapy and diagnosis, Adv Drug Deliv Rev. 54 (2002) 631-651. doi:10.1016/S0169-409X(02)00044-3.

[2] A.K. Iyer, G. Khaled, J. Fang, H. Maeda, Exploiting the enhanced permeability and retention effect for tumor targeting, Drug Discov Today. 11 (2006) 812-818. doi:10.1016/j.drudis.2006.07.005.

[3] R. Langer, Drug delivery and targeting, Nature. 392 (1998) 5-10. doi:10.1517/14728222.2.1.145.

[4] J.H. Na, H. Koo, S. Lee, K.H. Min, K. Park, H. Yoo, S.H. Lee, J.H. Park, I.C. Kwon, S.Y. Jeong, K. Kim, Real-time and non-invasive optical imaging of tumor-targeting glycol chitosan nanoparticles in various tumor models, Biomaterials. 32 (2011) 5252-5261. doi:10.1016/j.biomaterials.2011.03.076.

[5] X.B. Xiong, A. Lavasanifar, Traceable multifunctional micellar nanocarriers for cancertargeted co-delivery of MDR-1 siRNA and doxorubicin, ACS Nano. 5 (2011) 5202-5213. doi:10.1021/nn2013707.

[6] S. Radoslav, Z. Jinzi, A. Christine, M. Dusica, Nanomedicines Coming of Age: Recent Developments in Nanoneuroscience and Nano-Oncology, in: S. Dimitriu, V. Popa (Eds.), Polym Biomater, CRC Press, Boca Raton, FL, 2013: pp. 337-368.

[7] X. Zhu, E.L.B. Anquillare, O.C. Farokhzad, J. Shi, Polymer- and protein-based nanotechnologies for cancer theranostics, in: X. Chen, S. Wong (Eds.), Cancer Theranostics, Academic Press, Oxford, 2014: pp. 419-436.

[8] H.M. Aliabadi, A. Mahmud, A.D. Sharifabadi, A. Lavasanifar, Micelles of methoxy poly(ethylene oxide)-b-poly(e-caprolactone) as vehicles for the solubilization and controlled delivery of cyclosporine A, J Control Release. 104 (2005) 301-311. doi:10.1016/j.jconrel.2005.02.015.

[9] Y.Y. Diao, H.Y. Li, Y.H. Fu, M. Han, Y.L. Hu, H.L. Jiang, Y. Tsutsumi, Q.C. Wei, D.W. Chen, J.Q. Gao, Doxorubicin-loaded PEG-PCL copolymer micelles enhance cytotoxicity and intracellular accumulation of doxorubicin in adriamycin-resistant tumor cells., Int $\mathbf{J}$ Nanomedicine. 6 (2011) 1955-1962. doi:10.2147/IJN.S23099.

[10] M.A.R. Meier, S.N.H. Aerts, B.B.P. Staal, M. Rasa, U.S. Schubert, PEO-b-PCL block copolymers: Synthesis, detailed characterization, and selected micellar drug encapsulation behavior, Macromol Rapid Commun. 26 (2005) 1918-1924. doi:10.1002/marc.200500591.

[11] W. Qi, P.P. Ghoroghchian, G. Li, D.A. Hammer, M.J. Therien, Aqueous self-assembly of poly(ethylene oxide)-block-poly( $\varepsilon$-caprolactone) (PEO-b-PCL) copolymers: disparate diblock copolymer compositions give rise to nano- and meso-scale bilayered vesicles, Nanoscale. 5 (2013) 10908-10915. doi:10.1039/b000000x/This.

[12] R.T. Liggins, H.M. Burt, Polyether-polyester diblock copolymers for the preparation of paclitaxel loaded polymeric micelle formulations, Adv Drug Deliv Rev. 54 (2002) 191202. doi:10.1016/S0169-409X(02)00016-9.

[13] X. Zhang, J.K. Jackson, H.M. Burt, Development of amphiphilic diblock copolymers as micellar carriers of taxol, Int J Pharm. 132 (1996) 195-206. doi:10.1016/03785173(95)04386-1.

[14] B. Jeong, Y.H. Bae, S.W. Kim, In situ gelation of PEG-PLGA-PEG triblock copolymer 
aqueous solutions and degradation thereof, J Biomed Mater Res. 50 (2000) 171-177. doi:10.1002/(SICI)1097-4636(200005)50:2<171::AID-JBM11>3.0.CO;2-F.

[15] H.S. Yoo, T.G. Park, Biodegradable polymeric micelles composed of doxorubicin conjugated PLGA-PEG block copolymer, J Control Release. 70 (2001) 63-70. doi:10.1016/S0168-3659(00)00340-0.

[16] C. Oerlemans, W. Bult, M. Bos, G. Storm, J.F.W. Nijsen, W.E. Hennink, Polymeric micelles in anticancer therapy: Targeting, imaging and triggered release, Pharm Res. 27 (2010) 2569-2589. doi:10.1007/s11095-010-0233-4.

[17] S. Rameez, H. Alosta, A.F. Palmer, Biocompatible and biodegradable polymersome encapsulated hemoglobin: A potential oxygen carrier, Bioconjug Chem. 19 (2008) 10251032. doi: $10.1021 / \mathrm{bc} 700465 \mathrm{v}$.

[18] L. Yang, A. El Ghzaoui, S. Li, In vitro degradation behavior of poly(lactide)poly(ethylene glycol) block copolymer micelles in aqueous solution, Int J Pharm. 400 (2010) 96-103. doi:10.1016/j.ijpharm.2010.08.037.

[19] H. Lee, B. Hoang, H. Fonge, R.M. Reilly, C. Allen, In vivo distribution of polymeric nanoparticles at the whole-body, tumor, and cellular levels, Pharm Res. 27 (2010) 23432355. doi:10.1007/s11095-010-0068-Z.

[20] Z. Hu, F. Luo, Y. Pan, C. Hou, L. Ren, J. Chen, J. Wang, Y. Zhang, Arg-Gly-Asp (RGD) peptide conjugated poly(lactic acid)-poly(ethylene oxide) micelle for targeted drug delivery, J Biomed Mater Res - Part A. 85 (2008) 797-807. doi:10.1002/jbm.a.31615.

[21] H.C. Tsai, W.H. Chang, C.L. Lo, C.H. Tsai, C.H. Chang, T.W. Ou, T.C. Yen, G.H. Hsiue, Graft and diblock copolymer multifunctional micelles for cancer chemotherapy and imaging, Biomaterials. 31 (2010) 2293-2301. doi:10.1016/j.biomaterials.2009.11.059.

[22] A. Mahmud, X.-B. Xiong, A. Lavasanifar, Novel Self-Associating Poly (ethylene oxide)block -poly ( $\epsilon$-caprolactone ) Block Copolymers with Functional Side Groups on the Polyester Block for Drug Delivery, Macromolecules. 39 (2006) 9419-9428.

[23] S.M. Garg, M.R. Vakili, A. Lavasanifar, Polymeric micelles based on poly(ethylene oxide) and $\alpha$-carbon substituted poly( $\varepsilon$-caprolactone): An in vitro study on the effect of core forming block on polymeric micellar stability, biocompatibility, and immunogenicity, Colloids Surfaces B Biointerfaces. 132 (2015) 161-170.

doi:10.1016/j.colsurfb.2015.05.015.

[24] S.M. Garg, X. Xiong, C. Lu, A. Lavasanifar, Application of Click Chemistry in the Preparation of Poly (ethylene oxide) - block -poly ( $\varepsilon$-caprolactone ) with Hydrolyzable Cross-Links in the Micellar Core, Macromolecules. 44 (2011) 2058-2066. doi:10.1021/ma102548m.

[25] R. Soudy, A. Gill, T. Sprules, A. Lavasanifar, K. Kaur, Proteolytically stable cancer targeting peptides with high affinity for breast cancer cells, J Med Chem. 54 (2011) 75237534. doi:10.1021/jm200750x.

[26] A. Mahmud, A. Lavasanifar, The effect of block copolymer structure on the internalization of polymeric micelles by human breast cancer cells, Colloids Surfaces B Biointerfaces. 45 (2005) 82-89. doi:10.1016/j.colsurfb.2005.07.008.

[27] X.B. Xiong, A. Mahmud, H. Uludağ, A. Lavasanifar, Multifunctional polymeric micelles for enhanced intracellular delivery of doxorubicin to metastatic cancer cells, Pharm Res. 25 (2008) 2555-2566. doi:10.1007/s11095-008-9673-5.

[28] X.B. Xiong, Z. Ma, R. Lai, A. Lavasanifar, The therapeutic response to multifunctional polymeric nano-conjugates in the targeted cellular and subcellular delivery of 
doxorubicin, Biomaterials. 31 (2010) 757-768. doi:10.1016/j.biomaterials.2009.09.080.

[29] N. Kang, M.E. Perron, R.E. Prud'Homme, Y. Zhang, G. Gaucher, J.C. Leroux, Stereocomplex block copolymer micelles: Core-shell nanostructures with enhanced stability, Nano Lett. 5 (2005) 315-319. doi:10.1021/nl048037v.

[30] M. Shahin, R. Soudy, H.M. Aliabadi, N. Kneteman, K. Kaur, A. Lavasanifar, Engineered breast tumor targeting peptide ligand modified liposomal doxorubicin and the effect of peptide density on anticancer activity, Biomaterials. 34 (2013) 4089-4097. doi:10.1016/j.biomaterials.2013.02.019.

[31] C.R. Irwin, N.A. Favis, K.C. Agopsowicz, M.M. Hitt, D.H. Evans, Myxoma virus oncolytic efficiency can be enhanced through chemical or genetic disruption of the actin cytoskeleton, PLoS One. 8 (2013) e84134. doi:10.1371/journal.pone.0084134.

[32] J.J. Hue, H.J. Lee, S. Jon, S.Y. Nam, Y.W. Yun, J.S. Kim, B.J. Lee, Distribution and accumulation of Cy5.5-labeled thermally cross-linked superparamagnetic iron oxide nanoparticles in the tissues of ICR mice, J Vet Sci. 14 (2013) 473-479. doi:10.4142/jvs.2013.14.4.473.

[33] V. V. Rostovtsev, L.G. Green, V. V. Fokin, K.B. Sharpless, A stepwise huisgen cycloaddition process: Copper(I)-catalyzed regioselective "ligation" of azides and terminal alkynes, Angew Chemie - Int Ed. 41 (2002) 2596-2599. doi:10.1002/15213773(20020715)41:14<2596::AID-ANIE2596>3.0.CO;2-4.

[34] X.B. Xiong, A. Mahmud, H. Uludağ, A. Lavasanifar, Conjugation of arginine-glycineaspartic acid peptides to poly(ethylene oxide)-b-poly( $\varepsilon$-caprolactone) micelles for enhanced intracellular drug delivery to metastatic tumor cells, Biomacromolecules. 8 (2007) 874-884. doi:10.1021/bm060967g.

[35] Y. Liu, Y. Tseng, L. Huang, Biodistribution Studies of Nanoparticles Using Fluorescence Imaging: A Qualitative or Quantitative Method?, Pharm Res. 29 (2012) 3273-3277. doi:10.1007/s11095-012-0818-1.

[36] V.B. Rodriguez, S.M. Henry, A.S. Hoffman, P.S. Stayton, X. Li, S.H. Pun, Encapsulation and stabilization of indocyanine green within poly(styrene-alt-maleic anhydride) blockpoly(styrene) micelles for near-infrared imaging, J Biomed Opt. 13 (2008) 14025. doi:10.1117/1.2834296.

[37] D. Kim, E.S. Lee, K. Park, I.C. Kwon, Y.H. Bae, Doxorubicin loaded pH-sensitive micelle: Antitumoral efficacy against ovarian A2780/DOXR tumor, Pharm Res. 25 (2008) 2074-2082. doi:10.1007/s11095-008-9603-6.

[38] E. Blanco, C.W. Kessinger, B.D. Sumer, J. Gao, Multifunctional Micellar Nanomedicine for Cancer Therapy, Exp Biol Med. 234 (2009) 123-131. doi:10.3181/0808-MR-250.

[39] S.C. Owen, D.P.Y. Chan, M.S. Shoichet, Polymeric micelle stability, Nano Today. 7 (2012) 53-65. doi:10.1016/j.nantod.2012.01.002.

[40] R. Soudy, H. Etayash, K. Bahadorani, A. Lavasanifar, K. Kaur, Breast cancer targeting peptide binds keratin 1: A new molecular marker for targeted drug delivery to breast cancer, Mol Pharm. 14 (2017) 593-604. doi:10.1021/acs.molpharmaceut.6b00652.

[41] V. Askoxylakis, S. Zitzmann, W. Mier, K. Graham, S. Krämer, F. Von Wegner, R.H.A. Fink, M. Schwab, M. Eisenhut, U. Haberkorn, Preclinical evaluation of the breast cancer cell-binding peptide, p160, Clin Cancer Res. 11 (2005) 6705-6712. doi:10.1158/10780432.CCR-05-0432.

[42] M. Shahin, S. Ahmed, K. Kaur, A. Lavasanifar, Decoration of polymeric micelles with cancer-specific peptide ligands for active targeting of paclitaxel, Biomaterials. 32 (2011) 
5123-5133. doi:10.1016/j.biomaterials.2011.03.061.

[43] F. Alexis, E. Pridgen, L.K. Molnar, O.C. Farokhzad, Factors affecting the clearance and biodistribution of polymeric nanoparticles, Mol Pharm. 5 (2008) 505-515. doi: $10.1021 / \mathrm{mp} 800051 \mathrm{~m}$.

[44] J.E. Talmadge, R.K. Singh, I.J. Fidler, A. Raz, Murine Models to Evaluate Novel and Conventional Therapeutic Strategies for Cancer, Am J Pathol. 170 (2007) 793-804. doi:10.2353/ajpath.2007.060929.

[45] C. Wilmanns, D. Fan, C. Obrian, R. Radinsky, C. Bucana, R. Tsan, I. Fidler, Modulation of doxorubicin sensitivity and level of p-glycoprotein expression in human coloncarcinoma cells by ectopic and orthotopic environment in nude-mice, Int J Oncol. 3 (1993) 413-422.

[46] E.J. Chung, L.B. Mlinar, M.J. Sugimoto, K. Nord, B.B. Roman, M. Tirrell, In vivo biodistribution and clearance of peptide amphiphile micelles, Nanomedicine Nanotechnology, Biol Med. 11 (2015) 479-487. doi:10.1016/j.nano.2014.08.006.

[47] S. Kunjachan, R. Pola, F. Gremse, B. Theek, J. Ehling, D. Moeckel, B. HermannsSachweh, M. Pechar, K. Ulbrich, W.E. Hennink, G. Storm, W. Lederle, F. Kiessling, T. Lammers, Passive versus active tumor targeting using RGD- and NGR-modified polymeric nanomedicines, Nano Lett. 14 (2014) 972-981. doi:10.1021/n1404391r.

[48] M. Shokeen, E.D. Pressly, A. Hagooly, A. Zheleznyak, N. Ramos, A.L. Fiamengo, M.J. Welch, C.J. Hawker, C.J. Anderson, Evaluation of multivalent, functional polymeric nanoparticles for imaging applications, ACS Nano. 5 (2011) 738-747. doi:10.1021/nn102278w.

[49] C. Rangger, A. Helbok, E. von Guggenberg, J. Sosabowski, T. Radolf, R. Prassl, F. Andreae, G.C. Thurner, R. Haubner, C. Decristoforo, Influence of PEGylation and RGD loading on the targeting properties of radiolabeled liposomal nanoparticles, Int $\mathrm{J}$ Nanomedicine. 7 (2012) 5889-5900. doi:10.2147/ijn.s36847.

\section{Graphical Abstract}

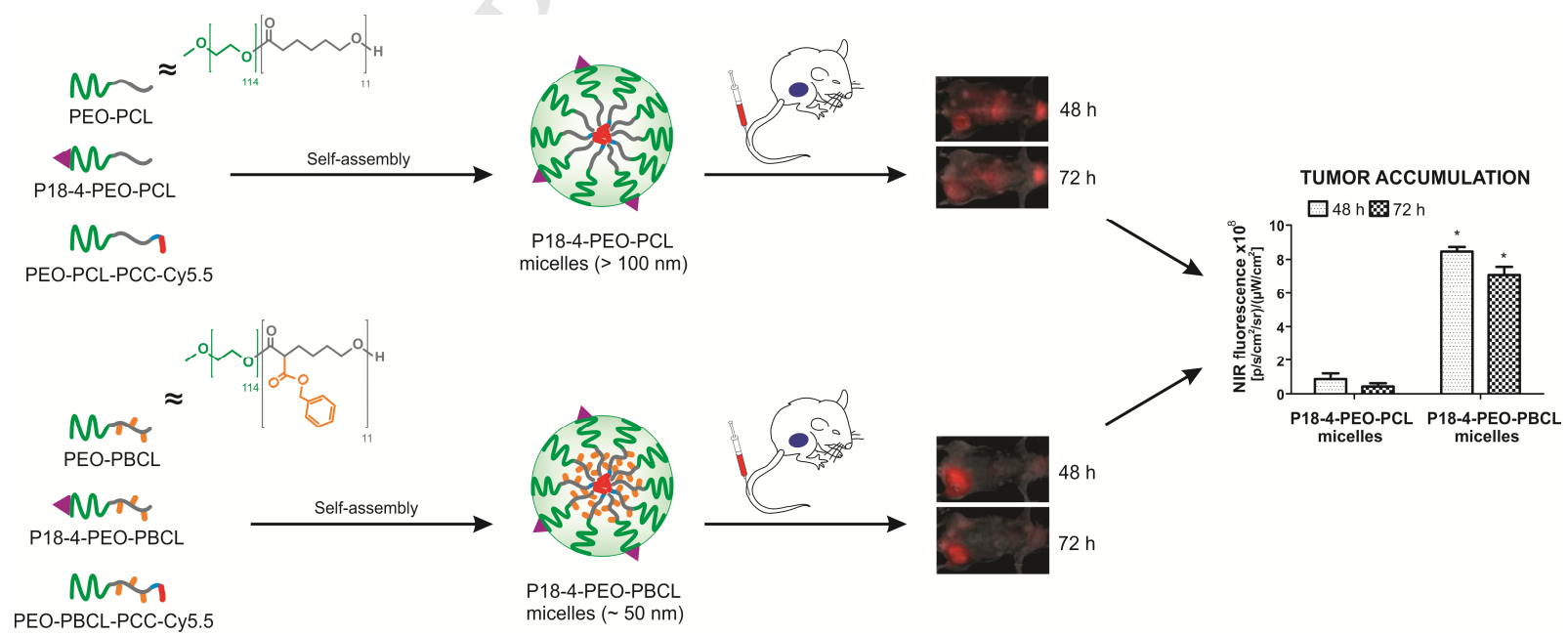

